Published in final edited form as:

Cryst Growth Des. 2016 November 2; 16(11): 6405-6418. doi:10.1021/acs.cgd.6b01078.

\title{
Why do Hydrates (Solvates) Form in Small Neutral Organic Molecules? Exploring the Crystal Form Landscapes of the Alkaloids Brucine and Strychnine
}

\author{
Doris E. Braun ${ }^{*}$ and Ulrich J. Griesser \\ Institute of Pharmacy, University of Innsbruck, Innrain 52c, 6020 Innsbruck, Austria
}

\begin{abstract}
Computational methods were used to generate and explore the crystal structure landscapes of the two alkaloids strychnine and brucine. The computed structures were analyzed and rationalized by correlating the modelling results to a rich pool of available experimental data. Despite their structural similarity, the two compounds show marked differences in the formation of solid forms. For strychnine only one anhydrous form is reported in the literature and two new solvates from 1,4-dioxane were detected in the course of this work. In contrast, 22 solid forms are so far known to exist for brucine, comprising two anhydrates, four hydrates ( $\mathbf{H y A}-\mathbf{H y C}$ and a 5.25-hydrate), twelve solvates (alcohols and acetone) and four heterosolvates (mixed solvates with water and alcohols). For strychnine it is hard to produce any solid form other than the stable anhydrate while the formation of specific solid state forms of brucine is governed by a complex interplay between temperature and relative humidity/water activity and it is rather a challenging to avoid hydrate formation. Differences in crystal packing and the high tendency for brucine to form hydrates are not intuitive from the molecular structure alone, as both molecules have hydrogen bond acceptor groups but lack hydrogen bond donor groups. Only the evaluation of the crystal energy landscapes, in particular the close-packed crystal structures and high-energy open frameworks containing voids of molecular (water) dimensions, allowed us to unravel the diverse solid state behavior of the two alkaloids at a molecular level. In this study we demonstrate that expanding the analysis of anhydrate crystal energy landscapes to higher energy structures and calculating the solventaccessible volume can be used to estimate non-stoichiometric or channel hydrate (solvate) formation, without explicitly computing the hydrate/solvate crystal energy landscapes.
\end{abstract}

\section{Keywords}

brucine; strychnine; hydrates; crystal structure prediction; void analysis

\footnotetext{
*Author to whom correspondence should be addressed: Dr. Doris E. Braun, Institute of Pharmacy, University of Innsbruck, Innrain 52c, 6020 Innsbruck, Austria, Tel: +43(0)512 507 58653, doris.braun@uibk.ac.at.

Associated Content

Computational search for guest-free strychnine and brucine forms (anhydrates); experimental screen for strychnine solvates/hydrates; strychnine 1,4-dioxane solvates: powder X-ray diffraction and thermogravimetric analysis; IR spectra of strychnine and brucine solid forms. This information is available free of charge via the Internet at http://pubs.acs.org/.

Author Contributions

The manuscript was written through contributions of all authors. All authors have given approval to the final version of the manuscript.
} 


\section{Introduction}

The solid form, referring to an anhydrate, solvate, hydrate or co-crystal, has a distinct impact on many physical and chemical properties of a chemical and, thus, influences manufacturing, long-term stability and performance of the product.1-7 Therefore, multidisciplinary solid form screening 4,8 is routinely performed in specialty chemical industries to ensure that forms with the best compromise of physical and chemical properties are developed. The study of all possible solvates (including hydrates) is important, as these solvent adducts can play a crucial role in which desolvation can generate new forms. Specific forms may only be accessible via the preliminary formation of the solvate.9-11 The investigation of hydrates is of particular importance, because water inevitably appears in the manufacturing and storage process of (drug) compounds and hydrate formation is known for at least one third of organic (drug) molecules.12-14 Therefore, generating knowledge of how water (vapor) is associated with a specific material and how it affects the stability of a product is a crucial task in preformulation studies.

A frequently applied hydrate classification system was proposed by Morris and RodriguezHornedo, 15,16 which groups hydrates based on their structures into three categories that are discernible by common analytical techniques: isolated site hydrates (water molecules are isolated from direct contact with each other), channel hydrates (chains of water molecules) and ion associated hydrates (metal ions are coordinated with water). Another, likewise often applied, hydrate classification is based on the moisture sorption/desorption behavior and divides the hydrates into two main classes, a) stoichiometric and b) non-stoichiometric hydrates. Stoichiometric hydrates have a well-defined water content. The water molecules are essential for the preservation of the hydrate structure and significant changes in the water/compound ratio entail a phase transition to a different crystal structure (anhydrous or other hydrate) or a non-crystalline product. In contrast, non-stoichiometric hydrates exhibit a distinct variability in composition within a certain range, which is not associated with a phase transition. Even significant changes in water content result only in weak changes of the crystal structure, mostly some anisotropic distortions of the network to accommodate water (expansion) or to reduce free volume resulting from water release (contraction). 17 Non-stoichiometric hydrates/solvates can be classified as a type of inclusion compounds 18 and in general, are more frequently observed for bulky molecules, with close-packing frustration.19 Non-stoichiometric hydrate formation is regarded an undesirable property in pharmaceutical development.20,21

Over the last decades crystal structure prediction (CSP) has evolved tremendously and is now used as a complement to experimental (industrial) solid form screening.22,23 The computationally generated crystal energy landscapes have rationalized and unified experimental observations on polymorphs, 10,24-31 solvates and hydrates.32-35 Yet, predicting solvates/inclusion compounds per se would be very complex and computationally (time) demanding, as host and different guest molecules in different stoichiometric ratios would have to be considered. Another approach is predicting the guest-free higher-energy structures and identifying the free accessible volume in the crystal structures.19,35 This approach is applied for the first time in the present work for a hydrate system (brucine36) forming both stoichiometric and non-stoichiometric hydrates. By choosing two chemically 
related systems (Figure 1) namely strychnine, forming no hydrate, and brucine, forming at least four different hydrate phases,37 it was possible to identify the range of structures on the computed brucine anhydrate crystal energy landscape, which might indicate nonstoichiometric or channel (like) hydrate/solvate formation.

Strychnine (strychnidin-10-one) and brucine (1,3-dimethoxystrychnidin-10-one) are well known alkaloids occurring in the seeds of the Stychnos nux-vomica tree.38 The compounds show therapeutic effects,39-44 albeit the narrow therapeutic window and high toxicity prohibit their use. The free bases of the two compounds are badly water soluble why a series of salts such as the $\mathrm{HCl}$, sulfate, etc. are known.38 Brucine may be used for stereospecific chemical syntheses and has been also used as an enantioselective recognition agent in chiral resolution.45,46 Famous names associated with strychnine are Sir Robert Robinson, for the determination of the chemical structure of strychnine (cation), and Robert B. Woodward, for the strychnine synthesis. Both chemists won the Nobel prize.47

Only one solid form (an anhydrate) can be found in literature for strychnine. Optical crystallographic data of this anhydrous form have already been reported in the compilation of Groth in 1919.48 Lattice parameters and space group of the same phase were reported in 1930 by Marwick (CSD-Refcode: ZZZUEE), 49 followed by full structure determinations performed by Golver (ZZZUEE01),50 Mostad (ZZZUEE02),51 Messerschmidt (ZZZUEE03- ZZZUEE06),52 and Zharylgasina (ZZZUE07).53 In contrast, brucine shows a rich solid form landscape: two anhydrates (MAJRIZ54 - a low temperature anhydrate $\mathbf{A H}_{\mathbf{L T}}$ and MAJRIZ0155- the commercially available AH), twelve solvates with organic solvents (JIFWEB,56 JIFWIF, 56 JIFWOL,56 JIFWUR,56 PIGNUP,56 PIGPAX,56 PIGPEB,56 PIGPIF,56 PIGPOL,56 PIGPUR,56 PIGQAY56 and MAJROF54), four heterosolvates ('mixed' solvates) with water and organic solvent molecules (DAFFUL,50 MAJRUL,54 HIDGOS57 and HIDGUY57), and four hydrates (HyA: dihydrate, CIKDOQ58; HyB: tetrahydrate, ZZZPRW01;59 HyC: 3.86-hydrate, YOYZIX55 ; a 5.25-hydrate: UCOJIG59). The $\mathbf{H y C}$ structure was published after we finished our experimental and computational work on this brucine phase.

This work expands our recent work37 on the three hydrates $\mathrm{HyA}, \mathrm{HyB}$ and $\mathrm{HyC}$ and neat brucine forms. The 5.25-hydrate was only obtained as a minor component in a mixture of brucine hydrates and was identified as a metastable hydrate phase under the investigated temperature and relative humidity (RH) conditions. Therefore, we focus in this study only on the three stable hydrates of brucine (HyA - HyC). In our previous study we showed that only a careful adjustment of RH/water activity $\left(a_{\mathrm{w}}\right)$ and temperature allows to control the formation of phase pure solid phases of brucine and to preserve these forms on storage. Furthermore, it could be shown that brucine shows a high tendency to hydrate formation, both in aqueous solutions as well as on exposure to moisture. 37 The present report now complements the pervious investigations by calculating the $Z^{\prime}=1 \& 2$ crystal energy landscapes of anhydrous brucine and strychnine. We aim to unravel the underlying reasons for (non-stoichiometric) hydrate formation and to answer the question why strychnine does not form a variety of crystal forms like brucine. Furthermore, by predicting the guest-free higher-energy structures and identifying the free accessible volume in the crystal structures we aim to unravel the $\mathbf{H y C}$ (framework) structure. More general, the goal is to incorporate 
CSP in solid state characterization and to extend our previous studies on stoichiometric hydrates,32,60-62 by predicting isomorphic desolvate structure(s).

\section{Materials and Methods}

\subsection{Materials}

Strychnine anhydrate (Lot. \# 30046) was purchased from Merck and used without further purification. A solvate screening programme was performed for strychnine. Suspensions of the anhydrate were prepared in 24 different solvents (Table S5 of the Supporting Information) and stirred in between 10 and $20^{\circ} \mathrm{C}$ (cycling) for 48 hours.

\subsection{Powder X-ray Diffraction}

PXRD patterns were obtained using an X'Pert PRO diffractometer (PANalytical, Almelo, $\mathrm{NL}$ ) equipped with a $\theta / \theta$ coupled goniometer in transmission geometry, programmable $\mathrm{XYZ}$ stage with a well plate holder, a $\mathrm{Cu}-\mathrm{Ka}_{1,2}$ radiation source with a focusing mirror, a $0.5^{\circ}$ divergence slit and a $0.02^{\circ}$ Soller slit collimator on the incident beam side, a $2 \mathrm{~mm}$ antiscattering slit and a $0.02^{\circ}$ Soller slit collimator on the diffracted beam side and a solid state PIXcel detector. The patterns were recorded at a tube voltage of $40 \mathrm{kV}$ and tube current of $40 \mathrm{~mA}$, applying a step size of $2 \theta=0.013^{\circ}$ with $80 \mathrm{~s}$ or $200 \mathrm{~s}$ per step in the $2 \theta$ range between $2^{\circ}$ and $40^{\circ}$. A VGI stage (VGI 2000M, Middlesex, UK) was used for non-ambient RH measurements.

\subsection{Computational Generation of the Crystal Energy Landscapes and Lattice Energy Calculations}

Conformational analysis was performed to restrict the search space to energetically meaningful regions for brucine. This was done by quantum mechanical (B3LYP/6-31G(d,p)) scans, using GAUSSIAN09,63 allowing torsions $\phi_{1}$ and $\phi_{2}\left(-\mathrm{OCH}_{3}\right.$ groups, Figure $\mathrm{S} 1$ of the Supporting Information) to rotate by $240^{\circ}$ in $30^{\circ}$ steps.

Hypothetical crystal structures of strychnine and brucine anhydrates $\left(Z^{\prime}=1 \& 2\right)$, were generated with the program CrystalPredictor.64-66 For strychnine 200,000 $Z^{\prime}=1$ and $500,000 \mathrm{Z}^{\prime}=2$ structures were generated randomly in seven space groups $\left(P 1, P 2_{1}, P 2_{1} 2_{1} 2\right.$, $P 2_{1} 2_{1} 2_{1}, C 2, C 222_{1}, P 222_{1}$ ), using the optimized molecular geometry (GAUSSIAN09, PBE0/6-31G(d,p)) and keeping the geometry rigid. The plausible range of conformational flexibility for brucine needed to be covered in the CrystalPredictor searches, covering the 120 to $+120^{\circ}$ torsional range for $\phi_{1}$ and the 60 to $300^{\circ}$ range for $\phi_{2}$ (Section 1.1 of the Supporting Information). For brucine $700,000 \mathrm{Z}^{\prime}=1$ and $2.800,000 \mathrm{Z}^{\prime}=2$ structures were generated covering the same seven space groups as for strychnine. The strychnine and brucine structures were relaxed to a local minimum in the intermolecular lattice energy, calculated from the FIT67 exp-6 repulsion-dispersion potential and atomic charges which had been fitted to electrostatic potential around the PBE0/6-31G(d,p) charge density using the CHELPG scheme.68

The energies of all structures within $40 \mathrm{~kJ} \mathrm{~mol}^{-1}$ of the global anhydrate lattice energy minima were refined $\left(370 \mathrm{Z}^{\prime}=1\right.$ and $1,238 \mathrm{Z}^{\prime}=2$ strychnine structures; $14,257 \mathrm{Z}^{\prime}=1$ and ca. 
$30,000 Z^{\prime}=2$ brucine structures), using DMACRYS69 with a more realistic, distributed multipole model70 for the electrostatic forces which had been derived using GDMA271 to analyze the PBE0/6-31G $(\mathrm{d}, \mathrm{p})$ charge density.

The ether functional group in strychnine and brucine, as well as the $-\mathrm{OCH}_{3}$ dihedral (Figure $\mathrm{S} 1$ of the Supporting Information) in the most stable brucine structures $\left(30 \mathrm{~kJ} \mathrm{~mol}^{-1}\right.$ range with respect to the global minima structures; strychnine: $101 \mathrm{Z}^{\prime}=1,660 \mathrm{Z}^{\prime}=2$ structures; brucine: $1,756 \mathrm{Z}^{\prime}=1,2,500 \mathrm{Z}^{\prime}=2$ structures) were minimized with the program CrystalOptimizer.72 Conformational energy penalties and isolated molecule charge densities were computed at the PBE0/6-31G(d,p) level.

DFT-D calculations were carried out with the CASTEP plane wave code73 using the Perdew-Burke-Ernzerhof (PBE) generalized gradient approximation (GGA) exchangecorrelation density functional74 and ultrasoft pseudopotentials, 75 with the addition of a semi-empirical dispersion correction, either the Tkatchenko and Scheffler (TS) model76 or Grimme06 (D2)77. In a first step, the predicted structures (strychnine: $39 \mathrm{Z}^{\prime}=1$ and $153 \mathrm{Z}$ ${ }^{\prime}=2,20 \mathrm{~kJ} \mathrm{~mol}^{-1}$ range with respect to the CrystalOptimizer global anhydrate structure; brucine all structures within the $10 \mathrm{~kJ} \mathrm{~mol}^{-1}$ range with respect to the CrystalOptimizer global anhydrate structure and all CrystalOptimizer structures having a density $\leq 1.320 \mathrm{~g}$ $\mathrm{cm}^{-3}$ within the $20 \mathrm{~kJ} \mathrm{~mol}^{-1}$ range: $85 \mathrm{Z}^{\prime}=1$ and $191 \mathrm{Z}^{\prime}=2$ ) were geometry optimized using the TS dispersion correction. Brillouin zone integrations were performed on a symmetrized Monkhorst-Pack $k$-point grid with the number of $k$-points chosen to provide a maximum spacing of $0.07 \AA^{-1}$ and a basis set cut-off of $560 \mathrm{eV}$. The self-consistent field convergence on total energy was set to $1 \times 10^{-5} \mathrm{eV}$. Energy minimizations were performed using the Broyden-Fletcher-Goldfarb-Shanno optimization scheme within the space group constraints. The optimizations were considered complete when energies were converged to better than $2 \times 10^{-5} \mathrm{eV}$ per atom, atomic displacements converged to $1 \times 10^{-3} \AA$, maximum forces to $5 \times 10^{-2} \mathrm{eV}^{-1}$, and maximum stresses were converged to $1 \times 10^{-1} \mathrm{GPa}$. The energies for all structures were recalculated, without optimization (unless stated otherwise), with the number of $k$-points chosen to provide a maximum spacing of $0.04 \AA^{-1}$ and a basis set cut-off of $780 \mathrm{eV}$, using the D2 dispersion correction, resulting in the final crystal energy landscapes. Isolated molecule minimizations to compute the isolated strychnine, brucine and $\mathrm{H}_{2} \mathrm{O}$ energies $\left(U_{\text {gas }}\right)$ were performed by placing a single molecule in a fixed cubic $35 \times 35 \times 35$ $\AA^{3}$ unit cell and optimized and recalculated with the same settings as used for the crystal calculations. All calculated structures were run through the ADDSYM function of PLATON78 in order to determine the true space group and $Z^{\prime}$ value.

PIXEL calculations79-81 were performed on the experimental anhydrates (PBE-TS optimized structures) to estimate the repulsive $\left(E_{\mathrm{R}}\right)$, dispersion $\left(E_{\mathrm{D}}\right)$, electrostatic (Coulombic, $E_{\mathrm{C}}$ ) and polarization $\left(E_{\mathrm{P}}\right)$ contributions from individual pairs of molecules within a crystal. An electron density map was calculated on a three-dimensional grid with a step size of $0.08 \AA$ at the MP2/6-31G(d,p) level using GAUSSIAN09 and a PIXEL condensation factor of 4 was applied.

Structural comparisons were made using the Packing similarity tool in the Solid Form module of Mercury to determine the root mean square deviation of the non-hydrogen atoms 
in a cluster of 15 molecules $\left(\mathrm{rmsd}_{15}\right) .82$ Furthermore, the relationships between crystal structures were examined using the XPac program.83,84 The results described in this work were obtained using all non-hydrogen atoms and routine medium cutoff parameters $\left(\delta_{\text {ang }}=\right.$ $10^{\circ}, \delta_{\text {tor }}$ and $\left.\delta_{\mathrm{dhd}}=18^{\circ}\right)$.

\section{Results and Discussion}

\subsection{Strychnine Solid Forms}

3.1.1 Strychnine Anhydrate-The molecular structure of the strychnine base consists of seven condensed rings (Figure 1), with only the phenyl ring being planar. The rigid molecule has four hydrogen bonding acceptor groups, two ternary $\mathrm{N}$ atoms, one ether and one carboxamide oxygen, but no hydrogen bonding donor functional group. Thus, there is no possibility for strong hydrogen bonding in strychnine. The only solid form, which has been identified and characterized to date crystallizes in the orthorhombic space group $P 22_{1} 2_{1}$, with $Z^{\prime}=1$ (Figure 2 ). The semi-classical density sums method was applied (intermolecular PIXEL energy79-81), which allows the calculation of interaction energies for molecule-molecule pairs and can be used to investigate the nature and strength of the intermolecular interactions. The molecule shape of strychnine allows a close packing (see section 3.3), with van der Waals interactions being the strongest contributor to the intermolecular PIXEL energy, $U_{\text {inter }}$ (Table 1).

3.1.2 Strychnine 1,4-Dioxane Solvates-Suspensions of strychnine in 24 solvents were stirred in between 10 and $20^{\circ} \mathrm{C}$ (cycling) for 48 hours (Table S5 of the Supporting Information). The 1,4-dioxane slurry experiment resulted in a new solvate of strychnine $\left(\mathbf{S}_{\mathbf{D x} 1}\right)$. All other experiments resulted in the known anhydrate phase. Upon storing the dioxane solvate for weeks at ambient conditions a slow transformation to a second solvate was observed $\left(\mathbf{S}_{\mathbf{D x} 2}\right)$. TGA and PXRD data are given in Section 6 of the Supporting Information. The known anhydrate form of strychnine was observed upon desolvation of the dioxane solvates. Thus, the presence of stoichiometric solvates can be assumed. The two solvates were not further characterized.

\subsection{Brucine Solid Forms}

The molecular structure of the brucine base differs from strychnine in that the phenyl ring is substituted with two $-\mathrm{OCH}_{3}$ groups (Figure 1), which adds two additional hydrogen bonding acceptors and two flexible groups compared to strychnine. The carbon atoms of the $-\mathrm{OCH}_{3}$ groups are nearly in plane with the phenyl ring and point in opposite directions in all structurally characterized brucine forms (Figure S2 of the Supporting Information). 50,5459 The latter conformation corresponds to a local energy minimum on the brucine potential energy surface and was calculated to be approx. $5 \mathrm{~kJ} \mathrm{~mol}^{-1}$ less stable than the global conformational energy minimum (see section 1.1 of the Supporting Information). So far, two anhydrous ( $\mathbf{A H}$ and $\mathbf{A H}_{\mathbf{L T}}$ ) and 20 solvate structures have been reported: four hydrates showing a different water:brucine ratio (2:1, 4:1, 3.86:1 and 5.25:1),55,58,59 and 16 solvates, including four mixed solvates.56,58,59,50,57 
Watabe et al.56 classified $\mathbf{A H}_{\mathbf{L T}}$ and solvates (not including $\mathbf{A H}$, the hydrates, mixed solvates and acetone solvate) into three groups based on packing similarity of the brucine frameworks, i.e GF (guest free), a-type (dimethanol solvate, JIFWEB56) and $\beta$-type (other alcohol solvates, Table S6 of the Supporting Information). We extended this classification with the ten other structures, resulting in eight distinct packing types.83 AH, HyA, HyC, 5.25-hydrate and the acetone solvate have distinct 3D packings, whereas the tetrahydrate (HyB) and two of the mixed solvates (DAFFUL50 and MAJRUL54) are isostructural with the dimethanol solvate (Table S6 of the Supporting Information). The other two heterosolvates (HIDGOS and HIDGUY57) are isostructural with the other alcohol solvates. The HyA, HyC and 5.25-hydrate are $Z^{\prime}=2$ structures, whereas all other structures are $Z^{\prime}=$ 1. Packing diagrams of the eight types are given in Figure 3 and the corresponding packing motifs in Figure 4. Types 1-3 have the same type of helical tapes, with types 1 and 2 only differing in the packing of left and right handed helical tapes. The 5.25-hydrate (type 3 ) forms alternating layers of left-handed helical tapes and a 2-fold motif (Figure 4). The acetone solvate shows $2_{1}$ stacks (type 5) and $\mathbf{H y A}$ a distinct $\mathrm{Z}^{\prime}=2$ packing motif (type 4). Structural features of the two brucine anhydrates and three hydrates ( $\mathbf{H y A}, \mathbf{H y B}$ and $\mathbf{H y C})$ are discussed in more detail in this section.

3.2.1 Brucine Anhydrates-The anhydrous form, $\mathbf{A H}$, of brucine was identified to be the thermodynamically most stable form at water activities $\left(a_{\mathrm{w}}\right)<0.4$ between 25 and $40{ }^{\circ} \mathrm{C}$. The phase can be observed directly in crystallization experiments or upon dehydration of HyC.37 The low temperature anhydrate $\left(\mathbf{A H}_{\mathbf{L T}}\right)$ has been reported to be enantiotropically related to $\mathbf{A H}$. The $\mathbf{A H}$ to $\mathbf{A H} \mathbf{L T}$ transformation occurs upon cooling at $-24{ }^{\circ} \mathrm{C}$ and the reversible $\mathbf{A H}_{\mathbf{L T}}$ to $\mathbf{A H}$ back transformation at $36{ }^{\circ} \mathrm{C}$ upon heating. 55 Slurry experiments in organic solvents showed that the thermodynamic transition point between the polymorphic pair $\mathbf{A H} / \mathbf{A H} \mathbf{H}_{\mathbf{L T}}$ is lower than $10^{\circ} \mathrm{C} .37$

In $\mathbf{A H}_{\mathbf{L T}}\left(P 2_{1}, \mathrm{Z}^{\prime}=1\right) 54$ and $\mathbf{A H}\left(P 2_{1}, \mathrm{Z}^{\prime}=1\right) 55$ the brucine molecules are arranged in corrugated monolayer sheets that run parallel to the (001) plane (Figure 5). The strongest pair-wise intermolecular interactions (derived from PIXEL energy calculations, Table 2) are located within these sheets, formed by left-handed helical tapes (Figure 4). The two anhydrates show a two-dimensional structural similarity and differ only in the threedimensional packing arrangement of identical sheets, i.e. shift of adjacent sheets (types 1a and $1 \mathrm{~b}$ in Figure 3).

Similar to strychnine, the van der Waals interactions were identified to be the strongest contributor to the $\mathbf{A H}_{\mathbf{L T}}$ and $\mathbf{A H}$ intermolecular PIXEL energies. The strongest strychnine pair-wise intermolecular interaction $\left(-36 \mathrm{~kJ} \mathrm{~mol}^{-1}\right.$, Table 1$)$ is, based on a molecular packing, comparable with the two strongest brucine interactions ( -46.5 or -43.1 and -33.8 or $-36.6 \mathrm{~kJ} \mathrm{~mol}^{-1}$, Table 2). Apart from that the strychnine anhydrate form adopts a different packing despite being chemically related. The brucine structures have a lower packing index compared to the strychnine structure (section 3.3), which can be related to the worse packing ability due to the additional $-\mathrm{OCH}_{3}$ groups.

3.2.2 Brucine Hydrates-The asymmetric unit of the dihydrate (HyA) structure58 comprises two independent brucine molecules and four water molecules. The water 
molecules are arranged in a tetrameric ring motif (graph-set84 notation: $\mathrm{R}_{4}^{4}(8)$, Figure 6), forming four strong $\mathrm{O}-\mathrm{H} \cdots \mathrm{O}$ hydrogen bonds. The tetrameric units are linked to adjacent units via a slightly weaker (longer) $\mathrm{O}-\mathrm{H} \cdots \mathrm{O}$ hydrogen bond and form hydrogen-bonded chains. The water molecules are located in channels running parallel to the crystallographic $b$ axis (Figure 6a). The two brucine molecules are linked to the water chains, either with $\mathrm{O}-$ $\mathrm{H} \cdots \mathrm{N}$ or $\mathrm{O}-\mathrm{H} \cdots \mathrm{O}$ hydrogen bonds. Dehydration of $\mathbf{H y A}$ results in an isomorphous dehydrate structure $\left(\mathbf{H y A}_{\mathbf{d e h y}}\right)$. This dehydrate is unstable and either rehydrates immediately to $\mathbf{H y A}$ if exposed to moisture or, if stored at very dry conditions (over desiccants such as $\mathrm{P}_{2} \mathrm{O}_{5}$ ) at ambient temperatures, a slow transformation to $\mathbf{A H}$ takes place. 37

The tetrahydrate (HyB, ZZZPRW0159) crystallizes in the orthorhombic space group $P 2_{1} 2_{1} 2_{1}$, with $Z^{\prime}=1$. The HyB structure belongs to the type 2a structures (Figure 3) and shows 1-dimensonal similarity with the two anhydrates, the left-handed helical tape. The four water molecules are arranged in channels propagating in direction of the crystallographic $a$ axis (Figure 7a). The water molecules form hexameric ring motifs (graphset84 notation: $\mathrm{R}_{6}^{6}(12)$, Figure $7 \mathrm{~b}$ ), with each of the eight water protons being involved in strong $\mathrm{O}-\mathrm{H} \cdots \mathrm{O} / \mathrm{N}$ hydrogen bonds. The hexameric units are linked to adjacent units via two strong $\mathrm{O}-\mathrm{H} \cdots \mathrm{O}$ hydrogen bonds and form a hydrogen-bonded chain. Three of the water molecules form H-bond interactions to brucine $(\mathrm{O}-\mathrm{H} \cdots \mathrm{O} / \mathrm{N})$. Dehydration of $\mathbf{H y B}$ results in amorphous brucine, which crystallizes depending on the external conditions to either $\mathbf{A H}$ or a mixture of hydrates. 37

The third hydrate, HyC (YOYZIX55), crystallizes in the form of thin long needles in the monoclinic space group $C 2$, with two brucine molecules in the asymmetric unit. $\mathbf{H y C}$ and the two anhydrate forms share sheets of the left-handed helical tapes (Figure 3). The other hydrates (HyA and $\mathbf{H y B}$ ) exhibit only 1D packing similarity with $\mathbf{A H}$. This may rationalize why $\mathbf{A H}$ is obtained directly upon dehydration of $\mathbf{H y C}$, whereas $\mathbf{A H}$ is only obtained upon dehydration from $\mathbf{H y A}$ or $\mathbf{H y B}$ via an intermediate phase, $\mathbf{H y A}_{\text {dehy }}$ or amorphous brucine. In contrast to the HyA and $\mathbf{H y B}$ structures' water channels the water molecules are arranged in pockets at isolated sites in $\mathbf{H y C}$ and form large 15- and 16-membered water clusters of cuboidal topology (Figure 8) as discussed in detail by Bialonska et al.55

\subsection{Computational Generation of Strychnine and Brucine Anhydrates}

3.3.1 Crystal Energy Landscapes-The experimental strychnine structure corresponds to the global energy minimum structure (Figure 9a) and was calculated to be $9.95 \mathrm{~kJ} \mathrm{~mol}^{-1}$ more stable than the second most stable (hypothetical) structure. The large energy gap implies that strychnine has one uniquely favorable way of packing into a close packed and stable 3D structure. Thus, the computed crystal energy landscape suggests, in agreement with the experiments, a monomorphic behavior for strychnine. The anhydrate does not show any phase changes upon cooling to $15 \mathrm{~K} 52$ or heating before sublimation, melting or decomposition.

Brucine $\mathbf{A H}_{\mathbf{L T}}$ corresponds to the global energy minimum structure and the enantiotropically related room temperature $\mathbf{A H}$ to the third lowest energy structure in Figure 9c. The energy gap of $\mathbf{A H}_{\mathbf{L T}}$ with respect to the second most stable calculated brucine 
structure is smaller $\left(3.42 \mathrm{~kJ} \mathrm{~mol}^{-1}\right)$ than for strychnine. Furthermore, thirteen structure were calculated to be within $10 \mathrm{~kJ} \mathrm{~mol}^{-1}$ of $\mathbf{A H}_{\mathbf{L T}}$, which is indicative for a polymorphic system. The energy difference between the two experimental anhydrates was calculated to be $3.72 \mathrm{~kJ}$ $\mathrm{mol}^{-1}$ at the PBE-D2 level of theory. The isostructural dehydrate $\left(\mathbf{H y}_{\mathbf{d}} \mathbf{d e h y}\right)$ can be found as a higher energy and lower density structure, albeit $20.15 \mathrm{~kJ} \mathrm{~mol}^{-1}$ less stable than $\mathbf{A H}_{\mathbf{L T}}$. All stages of lattice energy estimations correctly calculate $\mathbf{A H}_{\mathbf{L T}}$ and $\mathbf{A H}$ as more stable than $\mathbf{H y A}_{\text {dehy }}$ (Table S4 of the Supporting Information).

Six out of the 13 lowest energy structures have the left-handed helical tape as a structural building block (structures: $\mathbf{A H}_{\mathbf{L T}}, \mathbf{A H}, \mathrm{b4}, \mathrm{b6}$, b9 and b12; Table S2 of the Supporting Information). Five out of the latter six structures (all except b6) have the common brucine anhydrate building block, sheets of left-handed helical tapes. A comparison of the 13 computed lowest anhydrate structures and all of the brucine solvates (hydrates) revealed that each solvate structure shares a one-dimensional structural similarity with the selected computed lowest energy structures, either the helical tape or stacks of brucine molecules. Only $\mathbf{H y C}$ shows two-dimensional structural similarity with lowest energy structures (sheet of helical tapes), including its dehydration product. Higher structural resemblances between solvate and computed structures were observed albeit only among higher energy and more important lower density structures (see section 3.3.3).

The computed crystal energy landscapes are sufficiently realistic to reproduce the experimental structures (Table S3 of the Supporting Information) and key brucine packing motifs and thus, make it worthwhile contrasting the crystallization behavior of the two related compounds. The significant difference of the energy gaps between the lowest and second most stable calculated structures $\left(9.95 \mathrm{vs} .3 .42 \mathrm{~kJ} \mathrm{~mol}^{-1}\right)$ and the fact that the brucine crystal energy landscape has 13 structures within an energy range of $10 \mathrm{~kJ} \mathrm{~mol}^{-1}$ with respect to $\mathbf{A H}_{\mathbf{L T}}$ are suggestive of a more complex solid-state behavior of brucine. Even though brucine exhibits conformational flexibility (Section 1.1 of the Supporting Information), all of the 13 lowest energy structures can be related to the same (experimental) local energy minimum. Alternative crystal packings showing a conformation closely related to the global energy minimum conformation are possible, although the lattice energy is distinctively higher.

The two crystal energy landscapes have in common that the molecules are able to form densely packed structures (Section 1.2.1 of the Supporting Information, Figure 9). (The packing index of nearly $76 \%$ shows that the molecules pack more densely than close-packed spheres at 74\%). The experimental densities derived for the anhydrates from the single crystal structure determinations at $100 \mathrm{~K}$ are $1.389 \mathrm{~g} \mathrm{~cm}^{-3}$ for strychnine52 and $1.382 \mathrm{~g}$ $\mathrm{cm}^{-3}$ for brucine $\mathbf{A H}_{\mathbf{L T}} 54$. The $0 \mathrm{~K} \mathrm{AH}$ structure 55 of brucine shows a lower density of $1.345 \mathrm{~g} \mathrm{~cm}^{-3}(273 \mathrm{~K})$. On the lower PI range brucine has distinctly more stable (lower energy) packings than strychnine (Figure 9b,d). The 'void structures' may be indicative for the high tendency of solvate/hydrate10,24 formation of brucine. Thus, the two additional $\mathrm{OCH}_{3}$ groups of brucine influence the favorable ways of packing, and therefore crystallization, in that not only one unique dense packing motif may be expected but also framework structures that are sufficiently low in energy and have voids of molecular (water/ solvent) dimensions. To confirm that $\mathbf{H y A}_{\text {dehy }}$ is sufficiently low in energy to be considered 
as an experimental framework structure we estimated the energy differences between $\mathbf{H y A}$, $\mathbf{H y A}_{\text {dehy }}$ and $\mathbf{A H}$. This should give us the range of structures that have to be considered as putative channel or non-stoichiometric hydrates, provided solvent-accessible volume is present.

3.3.2 Enthalpy of HyA to $\mathrm{HyA}_{\text {dehy }}$ and AH transformation-The easiest way to define the energy range to consider for putative hydrate framework structures would be if experimental values for energy differences between isomorphic dehydrate and anhydrate structures were known. As this is not the case, transformation energies of hydrate to anhydrate phases/polymorphic transformation energies plus an uncertainty range may be used.

In a previous study 37 we used isothermal RH-perfusion calorimetry to estimate the brucine HyA to $\mathbf{H y A}_{\text {dehy }}$ transition enthalpy to be $5.3 \pm 0.9 \mathrm{~kJ} \mathrm{~mol}^{-1}$ (Table 3). On the other hand, measured transformation energies for stoichiometric dihydrates to anhydrates were determined to be higher (e.g.: phloroglucinol: $19.1 \mathrm{~kJ} \mathrm{~mol}^{-1}, 85$ barbituric acid: $17.0 \mathrm{~kJ}$ $\mathrm{mol}^{-1}, 86 \mathrm{DB}^{(\mathrm{z})}: 16.9 \pm 0.5 \mathrm{~kJ} \mathrm{~mol}^{-1}, 20$ codeine $\mathrm{HCl}^{2} 28.7 \pm 0.5 \mathrm{~kJ} \mathrm{~mol}^{-1}, 87$ etc.). Polymorphic transformation enthalpies may be expected within $10 \mathrm{~kJ} \mathrm{~mol}^{-1}$ or $10 \%$ of their lattice energy, however, higher values have been reported (e.g. DB7, $\Delta_{\text {trs }} H_{\text {III-II }}$ of -13.3 $\pm 0.2 \mathrm{~kJ} \mathrm{~mol}^{-1}$ ). 10 Higher transformations energies can be expected for isomorphic desolvate to stable anhydrate transformations. The reason therefore can be seen in the fact that isomorphic desolvate (dehydrate) structures are higher energy forms.

Computationally, an estimate for the dihydrate to anhydrate transition can be made by calculating the potential energy differences $(\Delta U)$ from the lattice energies of the hydrate, anhydrate and ice (ICE XI88) according to equ. (1).

$$
\Delta_{t r s} U_{H y A-X}=-E_{l a t t(H y A)}-\left(-E_{l a t t(X)}-2 E_{l a t t(I C E)}\right)
$$

With $\mathrm{X}$ corresponding to $\mathbf{H y A}_{\mathbf{d e h y}}$ or $\mathbf{A H}$. Table 3 lists the $\Delta U$ values of brucine $\mathbf{H y A}$, $\mathbf{H y} \mathbf{A}_{\text {dehy }}$ and $\mathbf{A H}$ calculated using different methods to estimate $E_{\text {latt }}$, based on ab initio electronic calculations on either the crystal $\left(\Psi_{\text {cry }}\right)$ or single molecule $\left(\Psi_{\text {mol }}\right)$. Using the lattice energies of the experimental structures and ICE XI (Table S4 of the Supporting Information) gives $\Delta_{\text {trs }} U_{\mathrm{HyA}-\mathrm{HyA} \text { (dehy) }}$ values ranging from 5.15 to $16.33 \mathrm{~kJ} \mathrm{~mol}^{-1}$ for the HyA to $\mathbf{H y A}_{\text {dehy }}$ transition enthalpy. The values derived by calculations on the single molecule, using a better wave function (PBE0 vs. $\mathrm{PBE}$ ), are quantitatively in better agreement with the experimental value of $5.3 \pm 0.9 \mathrm{~kJ} \mathrm{~mol}^{-1}$. The PBE-D2 energy estimate is also in good agreement with the experimental value, however, the PBE-TS method overestimates the energy. (The uncertainty of the modelling is dominated by the brucine $\cdots$ water interactions.89)

Differential scanning calorimetry (DSC) experiments in closed and open pans resulted in transition enthalpies of $3.0 \pm 0.9 \mathrm{~kJ} \mathrm{~mol}^{-1}$ and $2.4 \pm 1.0 \mathrm{~kJ} \mathrm{~mol}^{-1}$, respectively for the $\mathbf{H y A}$ to $\mathbf{A H}$ transformation. 37 As expected, the heat of transformation from a hydrate to a stable anhydrate phase is smaller than the transformation enthalpy to an unstable, higher energy 
(e.g. dehydrate) phase. For the $\mathbf{H y A}$ to $\mathbf{A H}$ transition, enthalpy energy values ranging from 0.16 to $-8.44 \mathrm{~kJ} \mathrm{~mol}^{-1}$ were derived using lattice energy calculations. Thus, the calculations wrongly suggest that $\mathbf{A H}$ is (slightly) more stable than HyA. The value derived by PBE-TS calculations is closest to the experimental value of 2.4 to $3.0 \mathrm{~kJ} \mathrm{~mol}^{-1}$, i.e. deviates by less than $3.2 \mathrm{~kJ} \mathrm{~mol}^{-1}$ (approx. 1.5\% of the $\mathbf{H y A}$ lattice energy). PBE-D2 and the calculations on the single molecule underestimate the stability of HyA significantly. The overall trend of the HyA lattice energy being underestimated may be related to the fact that entropy (water mobility37) contributes to the finite temperature energy. This term is neglected in the static 0 $\mathrm{K}$ lattice energy estimations used in this study.

Using the highest measured hydrate/anhydrate transition energy for the respective hydrate stoichiometry, i.e. the codeine $\mathrm{HCl}$ dihydrate to anhydrate dehydration energy of ca. $30 \mathrm{~kJ}$ $\mathrm{mol}^{-1} 87$, may be appropriate for identifying the energy range $\left(\Delta E_{\text {latt }}\right)$ for putative dehydrate structures whose max. water content is $2 \mathrm{~mol}$ of water per mol compound. This energy range has to be increased if higher hydrate stoichiometries or bigger guest molecules are targeted, e.g. brucine $\mathbf{H y B}, \mathbf{H y C}$ or 5.25-hydrate.

\subsubsection{Hydrate C Framework Structure Derived from Anhydrate Crystal Energy Landscape-The HyC structure was chosen to test whether guest-free higher-} energy structure predictions and free accessible volume analysis of the predicted structures, can be used to derive structural information of hydrates (solvates). By combining experimental analytical techniques and CSP the hydrate framework structure was derived and later the framework structure was compared to the experimental $\mathbf{H y C}$ structure, which was solved independently by another group. 55

Infrared spectroscopy (Section 7 of the Supporting Information) and indexation of the $\mathbf{H y C}$ powder X-ray diffraction pattern suggest the presence of a monoclinic unit cell with $Z^{\prime}=2$ $\left(a=25.018\right.$ (1) $\AA, b=12.381(<1) \AA, c=17.459(<1) \AA, \beta=122.20(<1)^{\circ}, \mathrm{V}=4576.11(31)$ $\left.\AA^{3}\right) .37$ With brucine being a chiral molecule, only three monoclinic space groups are possible, $P 2(\mathrm{Z}=2), P 2_{1}(\mathrm{Z}=2)$ and $C 2(\mathrm{Z}=4)$. Based on the volume of the indexed cell and the multiplicity of the possible space groups, $C 2$ (with $\mathrm{Z}^{\prime}=2$ and $\mathrm{Z}=8$ ) could be identified as the space group for $\mathbf{H y C}$.

The isomorphic dehydrate structure of $\mathbf{H y A}$ was found on the computed brucine anhydrate crystal energy landscape (Figure 9c). Therefore, we tested whether it is possible to find hypothetical $\mathbf{H y B}_{\text {dehy }}$ and $\mathbf{H y C}_{\mathbf{d e h y}}$ (isomorphic $\mathbf{H y B}$ and $\mathbf{H y C}$ dehydrate) structures among the higher energy and low density structures. None of the computed structures on Figure 9c gave a realistic match with the experimental $\mathbf{H y B}$ and $\mathbf{H y C}$ cells. Therefore, all generated higher energy structures (CrystalPredictor structures, see section 2.3) whose lattice parameters matched the $\mathbf{H y B}$ and $\mathbf{H y C}$ cells with an error of $\pm 20 \%$ were chosen and minimized as described in section 2.3. The computational $\mathbf{H y B}_{\text {dehy }}$ structure was successfully identified, albeit $35 \mathrm{~kJ} \mathrm{~mol}^{-1}$ higher in energy than $\mathbf{A H}$ (PBE-D2). The same approach resulted in two possible $\mathbf{H y} \mathbf{C}_{\mathbf{d e h y}}$ framework structures (Figure 10a\&b), that show 2-dimensional packing similarity. The common structural fragment includes the helical lefthanded tapes (Figure 4). $\mathbf{H y C}_{\text {dehy }} \mathbf{I}$ (Figure 10a) and $\mathbf{H y C}_{\text {dehy }} \mathbf{I I}$ (Figure 10b) may be classified as polytypes, i.e. the two packings differ in the location of every $4^{\text {th }}$ brucine layer, 
which is slightly shifted with respect to the common building block (three layers, highlighted in yellow in Figure 10 a,b) in the two structures. The two structures were calculated to be approx. $40 \mathrm{~kJ} \mathrm{~mol}^{-1}\left(\mathbf{H y C}_{\mathbf{d e h y}} \mathbf{I}\right)$ and $36 \mathrm{~kJ} \mathrm{~mol}^{-1}\left(\mathbf{H y C}_{\mathbf{d e h y}} \mathbf{I I}\right)$ less stable than $\mathbf{A H}$. Each of the two $\mathbf{H y C}_{\mathbf{d e h y}}$ structures shows 2D packing similarity with $\mathbf{A H}$.

The Hydrate Analyzer tool in Mercury was applied to identify water space in the two framework structures. The $\mathbf{H y C}_{\mathbf{d e h y}} \mathbf{I}$ framework shows channel-like void space (17.3\% of the unit cell volume, Figure 10c) and $\mathbf{H y} \mathbf{C}_{\mathbf{d e h y}} \mathbf{I I}$ isolated-site void space (18.6\% of the unit cell volume, Figure 10d). The reason for the different shape of the voice space arises from the small packing differences of brucine layers in the two structures (slight shift of every $4^{\text {th }}$ layer), as indicated with green arrows in Figures $10 \mathrm{c}$ and $\mathrm{d}$.

Powder patterns simulated from the computationally generated $\mathbf{H y} \mathbf{C}_{\mathbf{d e h y}}$ structures show a close match with the experimental $\mathbf{H y C}$ diffraction pattern. Based on the powder diffraction data comparisons it was not possible to conclude which of the two related framework structures may correspond to the $\mathbf{H y C}$ structure of brucine. Void space analysis in dependence of $\Delta E_{\text {latt }}$ suggests that $\mathbf{H y C}_{\mathbf{d e h y}} \mathbf{I I}$ is more likely (Figure 9d). The isolated-site void space would also rationalize the destructive dehydration mechanism to $\mathbf{A H}$. A structure comparison of $\mathbf{H y C}_{\text {dehy }} \mathbf{I}$ and $\mathbf{H y C}_{\text {dehy }} \mathbf{I I}$ with $\mathbf{H y C}$ finally revealed that $\mathbf{H y C}_{\text {dehy }} \mathbf{I I}$ corresponds to the experimental $\mathbf{H y C}$ framework structure.

\subsection{Reasons for the Differences in the Solid State Behavior of Strychnine and Brucine}

3.4.1 Different Crystallization Behavior-Despite being chemically related, strychnine and brucine differ significantly in the ability to form multiple solid forms, in particular the formation of solvates (hydrates). Strychnine can form solvates, two 1,4dioxane solvates, however, the solvates do not form readily and require the right experimental conditions with the first solvate being a transient solvate leading to a second 1,2-dioxane solvate polymorph. Brucine on the other hand is prone to solvate (hydrate) formation, in particular with solvent molecules providing hydrogen bond donor groups. All brucine solvates, with the exception of the acetone solvate, were obtained from alcohols or water. Preventing hydration of brucine requires adjusting the crystallization or storage conditions carefully, complicating handling and storing of the compound. Both compounds have in common that the most stable room temperature anhydrous forms are observed directly or via metastable intermediate phases (amorphous brucine or $\mathbf{H y} \mathbf{A}_{\text {dehy }}$ ) upon desolvating the solvates (hydrates). An isomorphic dehydrate can be produced for brucine $\left(\mathbf{H y A}_{\text {dehy }}\right)$, however, at room temperature this dehydrate exists only for a limited time at $0 \%$ $\mathrm{RH}$, making processing of this phase as a water free form practically impossible.

The strychnine and brucine anhydrate crystal energy landscapes confirm that the experimental anhydrates are amongst the most stable forms. For strychnine the energy gap between the lowest and second most stable calculated structure was found to be $10 \mathrm{~kJ} \mathrm{~mol}^{-1}$, which assures that the anhydrate is the only relevant neat form. Thus, only one $3 \mathrm{D}$ packing arrangement of the rigid molecule seems to be favorable. Furthermore, only two of the calculated structures in Figure 9a have a higher PI (packing index) than the experimental form, with the two structures being high in energy and approx. 17 and $24 \mathrm{~kJ} \mathrm{~mol}^{-1}$ less 
stable than the experimental phase. The stability of the experimental strychnine anhydrate can be attributed to the dense packing of the molecules. The anhydrate nucleates and grows rapidly, in agreement with the single favorable packing arrangement as shown in Figure 9a.

In contrast, the brucine crystal energy landscape (Figure 9c) suggests that there could be other (metastable) anhydrates, as there are several computed structures within the energy range expected for polymorphs (ignoring thermal effects). 94 The hypothetical polymorphs can be classified as 'packing polymorphs'. Despite the flexibility of the $-\mathrm{OCH}_{3}$ groups only the experimental conformation leads to stable packings. It cannot be excluded that other packing arrangements exist (e.g., second lowest energy structure on Figure 9) and it may also be possible that the right experiment just has not been performed yet.60,95,96 Or, it may not be possible to isolate the computed metastable structure(s) because the formation of $\mathbf{A H} / \mathbf{A H}_{\mathbf{L T}}$ may be favored by the fact that no conformational change is required to transform from a metastable to the stable form (i.e. short-lived intermediate phase, rearrangement during nucleation and growth). Finally, some of the predicted structures may not be energy minima at finite temperatures.98 In the case of brucine the crystallization of the anhydrate is complicated by the fact that (1) crystallization from numerous solvents leads to solvate formation, which subsequently desolvate to $\mathbf{A H}$ (either directly or via a high energy phase 37) and (2) that the hydrates are the thermodynamically most stable forms at water activities $\geq 0.4$ and ambient temperature. Thus, the crystallization conditions for generating other structures of anhydrous brucine are limited and require dry solvents.

The fact that crystallization experiments known to favor the formation of kinetic forms (desolvation process, crystallization form the amorphous state) resulted in $\mathbf{A H}, 37$ indicates that the latter phase, which is enantiotropically related to $\mathbf{A} \mathbf{H}_{\mathbf{L T}}$ (global 0K energy minimum) is not only a thermodynamic but also a kinetic crystallization product and might suggest that $\mathbf{A H}$ is the only observable anhydrate using conventional screening 99 conditions (> $10^{\circ} \mathbf{C}$, above the $\mathbf{A H} / \mathbf{A H} \mathbf{H}_{\mathbf{L T}}$ transition point).

3.4.2 Predicting Hydrate/Solvate Formation-At present, the computational generation of solvate (hydrate) crystal energy landscapes is extremely time consuming as both different guest molecules and different stoichiometric ratios have to be considered. Another approach is predicting the guest-free higher-energy structures and identifying framework structures that show free (accessible) volume.19,35

In Figures $9 \mathrm{~b} \& 8 \mathrm{~d}$ the lattice energy differences in dependence of the void space (free volume) of computed structures, with respect to the stable anhydrous forms, of two systems showing contrasting tendencies towards solvate/hydrate formation, are compared. The two crystal energy landscapes clearly indicate, at the molecular level, the differences in packing possibilities of the two chemically related compounds, which may be related to (nonstoichiometric or channel) solvate formation. The lack of predicted higher-energy low density structures for strychnine, in contrast to the same region on the brucine crystal energy landscape (Figure 9d), may be indicative for the fact that strychnine does not form channel or non-stoichiometric solvates. Thus, analyses of the higher-energy channel-like void structures on an anhydrate crystal energy landscape should be able to indicate solvate formation. 
It should be noted that the presence of coherent voids (channels) in a hydrate does not automatically imply, as often wrongly assumed, that a hydrate shows non-stoichiometric behavior. Examples for hydrates with channel-like voids but stoichiometric behavior are pyrogallol 0.25 -hydrate 100 or thymine 0.8 -hydrate. 11 The hydrate framework structures of these two hydrates were found as higher-energy structures on the anhydrate crystal energy landscapes, albeit the pyrogallol computational dehydrate structure was found among the more dense structures. On the other hand hydrates of DB7 (HyA),20 topotecan $\mathrm{HCl}, 101$ paroxetine $\mathrm{HCl}$ Form II102 or GSK's ApoA-1 up-regulator103 do not show coherent channels but their moisture sorption isotherms indicate clearly a non-stoichiometric behavior. Thus, not only void structures having continuous free accessible volume (in the form of channels), but also void space at isolated sites (in particular when the molecules show flexibility) have to be considered as putative solvate (hydrate) framework structures. Thererfore, the anhydrate crystal energy landscape may indicate solvate/hydrate formation, but the lack of structures with higher free (accessible) volume, within a certain energy range, does not automatically exclude the potential of solvate formation.

Defining a cut-off energy for putative computational desolvate structures has also been shown to be problematic. Table 4 lists $\Delta E_{\text {latt }}$ of the (hypothetical) isomorphic desolvate structures of brucine $\mathbf{H y A}-\mathbf{H y C}$ relative to $\mathbf{A H}$. Based on these data it can be deduced that (1) a higher water content correlates well with a higher void space (in \% of unit cell) and (2) a higher $\Delta E_{\text {latt }}$ value with respect to the stable $\mathbf{A H}_{\mathbf{L T}}$. The high values for $\Delta E_{\text {latt }}$ indicate, and warn us (!), that if one aims at predicting guest-free structures of higher stoichiometric solvates the energy range for generating the anhydrate crystal energy landscape must be expanded considerably compared to specific searches for anhydrate structures. The cut-off energies chosen for the generation of Figure $9 \mathrm{c}$ were not high enough for identifying the computational $\mathbf{H y B}$ and $\mathbf{H y C}$ dehydrate structures which demonstrates that a larger energy range is needed to include such structures in the analysis. Computational time can be reduced significantly by identifying channel-like structures showing sufficient void space to accommodate water (solvent) molecules at an early stage of CSP searches and not using density as a cut-off parameter. This will also reduce the number of structures used as starting points for (more) accurate lattice energy minimizations.

\subsubsection{Why does Brucine Show a High Tendency to Form Solvates}

(Hydrates)?-Solvate (hydrate) formation is often related to (i) either an unfavorable shape and larger size of molecules incapable of forming closely packed structures (ii) and/or well-connected hydrogen bond networks. In the case of brucine the molecules can pack reasonably well, as seen in $\mathbf{A H}$ and $\mathbf{A H}_{\mathbf{L T}}$. However, the direct comparison of the packing indices of the experimental and computed lowest energy structures of brucine with strychnine shows that the brucine structures have a lower packing index compared to the strychnine structures (Figure 9). Brucine features six hydrogen bonding acceptor groups but no hydrogen bonding donor group. Only by adding a second component with a hydrogen bond donor group the formation of strong $\mathrm{O} / \mathrm{N}-\mathrm{H} \cdots \mathrm{O} / \mathrm{N}$ intermolecular interactions is possible at all, as seen in the hydrate, alcohol and mixed solvate structures.50,54-59 A compassion of the strength of the strongest non-hydrogen bonded $\mathbf{A H} / \mathbf{A H}_{\mathbf{L T}}$ intermolecular interactions reveals that the brucine $\cdots$ brucine van der Waals interactions (pair wise PIXEL 
energies of $-46.5 \mathrm{~kJ} \mathrm{~mol}^{-} 1$, Table 2 ) are in the energy rage of $\mathrm{O}-\mathrm{H} \cdots \mathrm{O}$ hydrogen bonds. The high strength of the strongest non-hydrogen bonded brucine $\cdots$ brucine interactions rationalizes why anhydrous brucine is still highly competitive in stability with the hydrogen bonded solvate/hydrate structures. The fact that brucine shows a mismatch of hydrogen bond donor and acceptor groups does not necessarily account for the high tendency for solvate (hydrate) formation. The acceptor groups involved in the majority of the hydrogen bond interactions in the brucine solvate structures are also present in strychnine. However, strychnine, does not show a high tendency towards hydrate/solvate formation. The only strychnine solvates identified so far are 1,4-dioxane solvates, with strychnine and 1,4dioxane not being able to form strong hydrogen bonds. Thus, the different hydrate/solvate formation propensity for the two chemically related alkaloids may be related to the packing efficiency (and stability) of the neat forms. The latter can be derived from the computed anhydrate crystal energy landscapes.

\section{Conclusions}

The two chemically related alkaloids strychnine and brucine differ markedly in their tendency to form solvates/hydrates, as seen experimentally and derived from the evaluation of the low and higher-energy structures on their crystal energy landscapes. The comparison of the sets of predicted low energy structures can help to anticipate likely packing modes and whether changes in packing can be induced by chemically modifying the molecular building block. In the case of the studied compounds the differences in the substitution of the phenyl ring (strychnine: $-\mathrm{H}$; brucine:- $\mathrm{OCH}_{3}$ groups) significantly influences the molecule packing propensities. Strychnine forms one favorable packing arrangement (experimental anhydrate), with alternative hypothetical structures being distinctly higher in energy $\left(10 \mathrm{~kJ} \mathrm{~mol}^{-1}\right)$, but still densely packed. The most stable neat brucine packing arrangement $\left(\mathbf{A H}_{\mathbf{L T}}\right)$ is also a close packed structure, but energetically competitive hypothetical structures already show packing frustration. The latter can be compensated for by the formation of hydrates/alcohol solvates, i.e. the formation of multi-component crystals with guest molecules featuring hydrogen bond donor groups.

Crystal structure prediction calculations on the host molecule alone, combined with an analysis of relative lattice energies in dependence of (free) accessible channel-like volume, can be used to propose framework candidates, as shown for the $\mathbf{H y C}$, for which the guestfree structure model was one the two suggested candidate structures. The guest-free modelling approach overcomes the huge cost of calculating the crystal energy landscapes in multicomponent systems. In general, the (free) accessible volume analysis of the (guest-free) crystal energy landscape has the potential to indicate non-stoichiometric or channel solvate (hydrate) formation. However, the absence of (free) accessible volume structures does not necessarily imply that a compound won't be able to form solvates (hydrates), which is demonstrated by the discovered strychnine 1,4-dioxane solvates.

Further developments and approaches for successfully calculating the relative stability of crystal structures at finite temperature rather than using static $0 \mathrm{~K}$ lattice energy estimation 104,105 are required. This is in particular true for hydrate (solvate)/anhydrate system, where water/solvent mobility significantly contributes to the crystal energy, as 
shown for brucine HyA. Nevertheless, this study is another demonstration22,23 that CSP methods have considerably advanced in recent years to a stage of complementing and elucidating experimental findings, which permits access to a better fundamental understanding of the potential of small organic molecules forming different supramolecular assemblies.

\section{Supplementary Material}

Refer to Web version on PubMed Central for supplementary material.

\section{Acknowledgment}

The authors are grateful to Prof. S. L. Price (University College London) for scientific discussions and the use of the DMACRYS program and to Profs. C. C. Pantelides and C. S. Adjiman (Imperial College London) for the use of the CrystalPredictor and CrystalOptimizer programs. D.E.B. gratefully acknowledges funding by the Elise Richter Programme of the Austrian Science Fund (FWF, project V436-N34). The computational results presented have been achieved using the HPC infrastructure LEO of the University of Innsbruck.

\section{References}

1. Bernstein, J. Polymorphism in Molecular Crystals. Clarendon Press; Oxford: 2002.

2. Byrn, SR., Pfeiffer, RR., Stowell, JG. Solid-State Chemistry of Drugs. West Lafayette, Indiana: 1999.

3. Brittain, HG. Polymorphism in Pharmaceutical Solids. Vol. 192. Informa Healthcare; New York, London: 2009.

4. Hilfiker, R. Polymorphism in the Pharmaceutical Industry. Wiley-VCH; Weinheim: 2006.

5. Singhal D, Curatolo W. Adv Drug Deliver Rev. 2004; 56:335-347.

6. Blagden N, Matas M, Gavan PT, York P. Adv Drug Deliver Rev. 2007; 59:617-630.

7. Zalte AG, Darekar AB, Gondkar SB, Saudagar RB. Am J PharmTech Res. 2014; 4

8. Storey, RA., Ymén, I. Solid state characterization of pharmaceuticals. Wiley; Chichester: 2012.

9. Stephenson GA, Stowell JG, Toma PH, Dorman DE, Greene JR, Byrn SR. Solid-State Analysis of Polymorphic, Isomorphic, and Solvated Forms of Dirithromycin. J Am Chem Socl. 1994; 116:5766-5773.

10. Braun DE, McMahon JA, Koztecki LH, Price SL, Reutzel-Edens SM. Cryst Growth Des. 2014; 14:2056-2072.

11. Braun DE, Gelbrich T, Wurst K, Griesser UJ. Cryst Growth Des. 2016; 16:3480-3496.

12. Stahly GP. Cryst Growth Des. 2007; 7:1007-1026.

13. Braun, DE. Crystal polymorphism andf structure property relationships of drug compounds. University of Innsbruck; 2008.

14. Cruz-Cabeza AJ, Reutzel-Edens SM, Bernstein J. Chem Soc Rev. 2015; 44:8619-8635. [PubMed: 26400501]

15. Brittain, HG., Morris, KR., Boerrigter, SXM. Polymorphism in Pharmaceutical Solids. Vol. 192. Informa Healthcare; New York: 2009. p. 233-281.

16. Morris, KR., Rodriguez-Hornedo, N. Encyclopedia of Pharmaceutical Technology. Swarbrick, J., Boylan, J., editors. Marcel Dekker; New York: 1993. p. 393-440.

17. Gal S. Chimia. 1968; 22:409-425.

18. Griesser, UJ. Polymorphism: In the Pharmaceutical Industry. Hilfiker, R., editor. Wiley-VCH; Germany: 2006. p. 211-233.

19. Cruz-Cabeza AJ, Day GM, Jones W. Chem Eur J. 2009; 15:13033-13040. [PubMed: 19876969]

20. Braun DE, Koztecki LH, McMahon JA, Price SL, Reutzel-Edens SM. Mol Pharm. 2015; 12:3069_ 3088. [PubMed: 26075319]

21. Bauer JF, Dziki W, Quick JE. J Pharm Sci. 1999; 88:1222-1227. [PubMed: 10564073] 
22. Price SL, Reutzel-Edens SM. Drug Discov Today. 2016

23. Price SL, Braun DE, Reutzel-Edens SM. Chem Commun. 2016; 52:7065-7077.

24. Bhardwaj RM, Price LS, Price SL, Reutzel-Edens SM, Miller GJ, Oswald IDH, Johnston B, Florence AJ. Cryst Growth Des. 2013; 13:1602-1617.

25. Baias M, Dumez JN, Svensson PH, Schantz S, Day GM, Emsley L. J Am Chem Soc. 2013; 135:17501-17507. [PubMed: 24168679]

26. Singh SS, Thakur TS. CrystEngComm. 2014; 16:4215-4230.

27. Price LS, McMahon JA, Lingireddy SR, Lau SF, Diseroad BA, Price SL, Reutzel-Edens SM. J Mol Struct. 2014; 1078:26-42.

28. Campeta AM, Chekal BP, Abramov YA, Meenan PA, Henson MJ, Shi B, Singer RA, Horspool KR. J Pharm Sci. 2010; 99:3874-3886. [PubMed: 20575000]

29. Kendrick J, Stephenson GA, Neumann MA, Leusen FJ. Cryst Growth Des. 2013; 13:581-589.

30. Abramov YA. Org Process Res Dev. 2013; 17:472-485.

31. Fakes MG, Vakkalagadda BJ, Qian F, Desikan S, Gandhi RB, Lai C, Hsieh A, Franchini MK, Toale H, Brown J. Int J Pharm. 2009; 370:167-174. [PubMed: 19100319]

32. Braun DE, Karamertzanis PG, Price SL. Chem Commun. 2011; 47:5443-5445.

33. Cruz-Cabeza AJ, Day GM, Jones W. Chem Eur J. 2008; 14:8830-8836. [PubMed: 18752227]

34. Cruz-Cabeza AJ, Karki S, Fabian L, Friscic T, Day GM, Jones W. Chem Commun. 2010; 46:22242226.

35. Pyzer-Knapp EO, Thompson HPG, Schiffmann F, Jelfs KE, Chong SY, Little MA, Cooper AI, Day GM. Chem Sci. 2014; 5:2235-2245.

36. Hartwick C, Geiger P. Arch Pharm. 1901; 239:491.

37. Braun DE, Griesser UJ. Cryst Growth Des. 2016 http://dx.doi.org/10.1021.

38. The Merck Index. 14th ed. Merck Inc; Whitehouse Station, NJ: 2006. [Online]

39. Agrawal SS, Saraswati S, Mathur R, Pandey M. Life Sci. 2011; 89:147-158. [PubMed: 21684292]

40. Chen, Hb, Ma, Fs, Fang, Jq, Fang, F. Zhongchengyao. 2015; 37:16-21.

41. Deng XK, Yin W, Li WD, Yin FZ, Lu XY, Zhang XC, Hua ZC, Cai BC. J Ethnopharmacol. 2006; 106:179-186. [PubMed: 16442763]

42. Yin W, Deng XK, Yin FZ, Zhang XC, Cai BC. Food Chem Toxicol. 2007; 45:1700-1708. [PubMed: 17449162]

43. Rao PS, Ramanadham M, Prasad MNV. Food Chem Toxicol. 2009; 47:283-288. [PubMed: 19027818]

44. Chen J, Wang X, Qu Yg, Chen Zp, Cai H, Liu X, Xu F, Lu Tl, Cai BC. J Ethnopharmacol. 2012; 139:181-188. [PubMed: 22094056]

45. Quinkert G, Schmalz HG, Dzierzynski EM, Duerner G, Bats JW. Angew Chem. 1986; 98:10231024.

46. Boiadjiev SE, Person RV, Puzicha G, Knobler C, Maverick E, Trueblood KN, Lightner DA. J Am Chem Soc. 1992; 114:10123-10133.

47. Gupta, RC., Patocka, J. Handbook of Toxicology of Chamical Warfare Agents. Academic Press; London: 2009.

48. Groth, P. Chemische Krystallographie. Teil 5. Aromatische Kohlenstoffverbindungen mit mehreren Benzolringen heterocyclische Verbindungen. Vol. 5. Engelmann, W; Leipzig, Germany: 1919.

49. Marwick TC. Nature (London, U. K.). 1930; 126:438.

50. Glover SSB, Gould RO, Walkinshaw MD. Acta Crystallogr, Sect C: Cryst Struct Commun. 1985; C41:990-994.

51. Mostad A. Acta Chem Scand, Ser B. 1985; B39:705-716.

52. Messerschmidt M, Scheins S, Luger P. Acta Crystallogr, Sect B: Struct Sci. 2005; B61:115-121.

53. Zharylgasina GT, Musina LA, Bagryanskaya IY, Shakirov MM, Tuleuov BI, Shul'ts EE, Adekenov SM. Chem Nat Compd. 2010; 46:154-157.

54. Bialonska A, Ciunik Z. Acta Crystallogr, Sect C: Cryst Struct Commun. 2004; C60:o853-o855. 55. Bialonska A, Ciunik Z, Ilczyszyn MM, Siczek M. Cryst Growth Des. 2014; 14:6537-6541. 
56. Watabe T, Kobayashi K, Hisaki I, Tohnai N, Miyata M. Bull Chem Soc Jpn. 2007; 80:464-475.

57. Bialonska A, Ciunik Z. CrystEngComm. 2013; 15:5681-5687.

58. Smith G, Wermuth UD, White JM. Acta Crystallogr C. 2007; 63:o489-o492. [PubMed: 17675704]

59. Smith G, Wermuth UD, Healy PC, White JM. Acta Crystallogr, Sect C: Cryst Struct Commun. 2006; C62:o203-o207.

60. Braun DE, Oberacher H, Arnhard K, Orlova M, Griesser UJ. CrystEngComm. 2016; 18:40534067. [PubMed: 28649176]

61. Braun DE, Nartowski KP, Khimyak YZ, Morris KR, Byrn SR, Griesser UJ. Mol Pharm. 2016; 13:1012-1029. [PubMed: 26741914]

62. Braun DE, Orlova M, Griesser UJ. Cryst Growth Des. 2014; 14:4895-4900.

63. Frisch, MJ., Trucks, GW., Schlegel, HB., Scuseria, GE., Robb, JMA., Cheeseman, R., Scalmani, G., Barone, V., Mennucci, B., Petersson, GA., Nakatsuji, H., et al. Gaussian 09. Gaussian Inc; Wallingford CT: 2009.

64. Karamertzanis PG, Pantelides CC. J Comput Chem. 2005; 26:304-324. [PubMed: 15622548]

65. Karamertzanis PG, Pantelides CC. Molecular Physics. 2007; 105:273-291.

66. Habgood M, Sugden IJ, Kazantsev AV, Adjiman CS, Pantelides CC. J Chem Theory Comput. 2015; 11:1957-1969. [PubMed: 26574397]

67. Coombes DS, Price SL, Willock DJ, Leslie M. J Phys Chem. 1996; 100:7352-7360.

68. Breneman CM, Wiberg KB. J Comput Chem. 1990; 11:361-373.

69. Price SL, Leslie M, Welch GWA, Habgood M, Price LS, Karamertzanis PG, Day GM. Phys Chem Chem Phys. 2010; 12:8478-8490. [PubMed: 20607186]

70. Stone AJ. J Chem Theory Comput. 2005; 1:1128-1132. [PubMed: 26631656]

71. Stone, AJ., editor. GDMA: A Program for Performing Distributed Multipole Analysis of Wave Functions Calculated Using the Gaussian Program System, version 2.2. University of Cambridge; Cambridge, United Kingdom: 2010.

72. Kazantsev AV, Karamertzanis PG, Adjiman CS, Pantelides CC. J Chem Theory Comput. 2011; 7:1998-2016. [PubMed: 26596459]

73. Clark SJ, Segall MD, Pickard CJ, Hasnip PJ, Probert MJ, Refson K, Payne MC. Z Kristallogr. 2005; 220:567-570.

74. Perdew JP, Burke K, Ernzerhof M. Phys Rev Lett. 1996; 77:3865-3868. [PubMed: 10062328]

75. Vanderbilt D. Phys Rev B. 1990; 41:7892-7895.

76. Tkatchenko A, Scheffler M. Phys Rev Lett. 2009; 102 073005-1-073005/4.

77. Grimme S. J Comput Chem. 2006; 27:1787-1799. [PubMed: 16955487]

78. Spek, AL., editor. PLATON, A Multipurpose Crystallographic Tool. Utrecht University; Utrecht, The Netherlands: 2003.

79. Gavezzotti A. New J Chem. 2011; 35:1360-1368.

80. Gavezzotti A. J Phys Chem B. 2002; 106:4145-4154.

81. Gavezzotti A. J Phys Chem B. 2003; 107:2344-2353.

82. Chisholm JA, Motherwell S. J Appl Crystallogr. 2005; 38:228-231.

83. Numbers $(1,2, .$.$) indicate the classes and letters (a, b)$ the subclasses. Subclasses are used for types that differ only in the packing of the same fragments, e.g. AH and $\mathbf{A H} \mathbf{L T}$.

84. Etter MC, MacDonald JC, Bernstein J. Acta Crystallogr, Sect B. 1990; 46:256-262. [PubMed: 2344397]

85. Braun DE, Tocher DA, Price SL, Griesser UJ. J Phys Chem B. 2012; 116:3961-3972. [PubMed: 22390190]

86. Zencirci N, Gstrein E, Langes C, Griesser UJ. Thermochim Acta. 2009; 485:33-42.

87. Braun DE, Gelbrich T, Kahlenberg V, Griesser UJ. Mol Pharm. 2014; 11:3145-3163. [PubMed: 25036525]

88. Jackson SM, Nield VM, Whitworth RW, Oguro M, Wilson CC. J Phys Chem B. 1997; 101:61426145 . 
89. Brucine $\cdots$ brucine interactions are the same in $\mathbf{H y A}$ and $\mathbf{H y} \mathbf{A}_{\text {dehy }}$ and the water interactions in HyA are ice-like water' ${ }^{\prime}$ water interactions.

90. Cossi M, Scalmani G, Rega N, Barone V. J Chem Phys. 2002; 117:43-45.

91. Cossi M, Barone V, Mennucci B, Tomasi J. Chem Phys Lett. 1998; 286:253-260.

92. Mennucci B, Tomasi J. J Chem Phys. 1997; 106:5151-5158.

93. Cooper TG, Hejczyk KE, Jones W, Day GM. J Chem Theory Comput. 2008; 4:1795-1805. [PubMed: 26620182]

94. Price SL. Chem Soc Rev. 2014; 43:2098-2111. [PubMed: 24263977]

95. Arlin JB, Price LS, Price SL, Florence AJ. Chem Commun. 2011; 47:7074-7076.

96. Zencirci N, Gelbrich T, Kahlenberg V, Griesser UJ. Cryst Growth Des. 2009; 9:3444-3456.

97. Price SL. Acta Crystallogr, Sect B. 2013; 69:313-328.

98. Karamertzanis PG, Raiteri P, Parrinello M, Leslie M, Price SL. J Phys Chem B. 2008; 112:42984308. [PubMed: 18341322]

99. Llinas A, Goodman JM. Drug Discover Today. 2008; 13:198-210.

100. Braun DE, Bhardwaj RM, Arlin JB, Florence AJ, Kahlenberg V, Griesser UJ, Tocher DA, Price SL. Cryst Growth Des. 2013; 13:4071-4083.

101. Vogt FG, Dell'Orco PC, Diederich A, Su Q, Wood JL, Zuber GE, Katrincic LM, Mueller RL, Busby DJ, DeBrosse CW. J Pharm Biomed Anal. 2006; 40:1080-1088. [PubMed: 16242889]

102. Pina MF, Pinto JF, Sousa JJ, Fabian L, Zhao M, Craig DQM. Mol Pharm. 2012; 9:3515-3525. [PubMed: 23051151]

103. Kang F, Vogt FG, Brum J, Forcino R, Copley RCB, Williams G, Carlton R. Cryst Growth Des. 2012; 12:60-74.

104. Nyman J, Pundyke OS, Day GM. Phys Chem Chem Phys. 2016; 18:15828-15837. [PubMed: 27230942]

105. Reilly AM, Cooper RI, Adjiman CS, Bhattacharya S, Boese AD, Brandenburg JG, Bygrave PJ, Bylsma R, Campbell JE, Car R, Case DH, et al. Acta Crystallogr, Sect B: Struct Sci, Cryst Eng Mater. 2016; 72:439-459. 


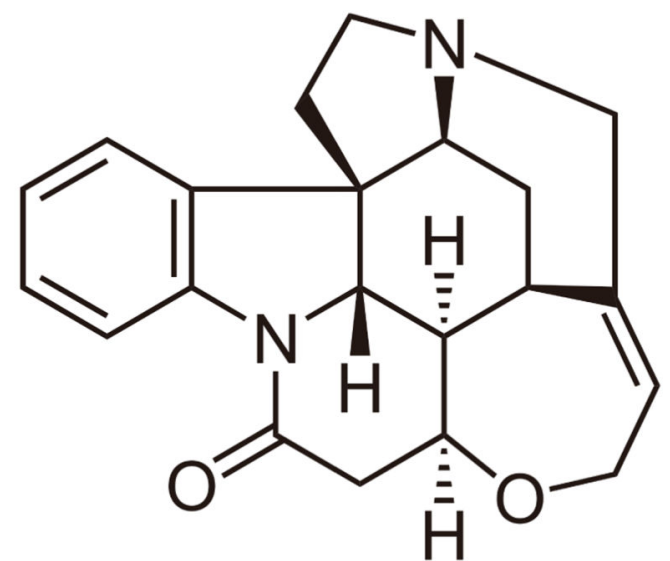

strychnine (s)

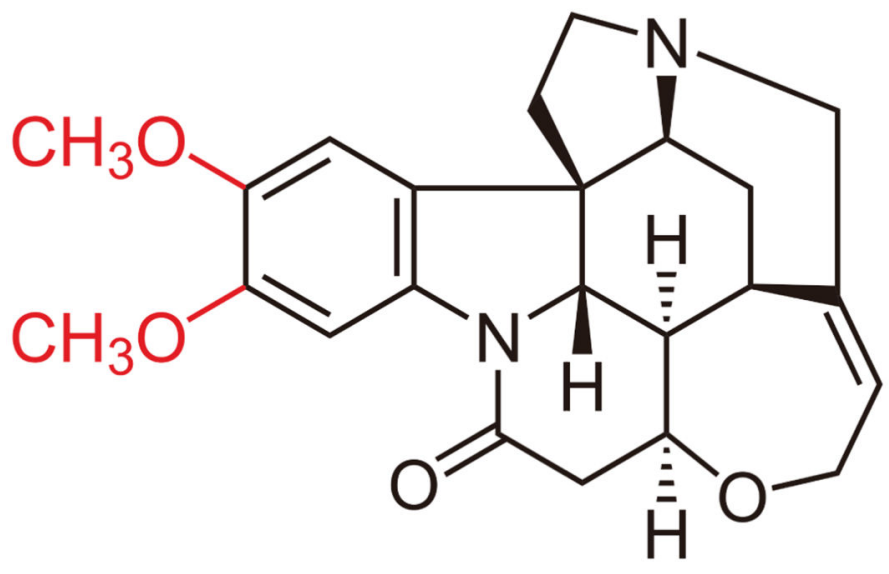

brucine (b)

Figure 1.

Molecular diagrams of the two alkaloids being studied, strychnine and brucine. 


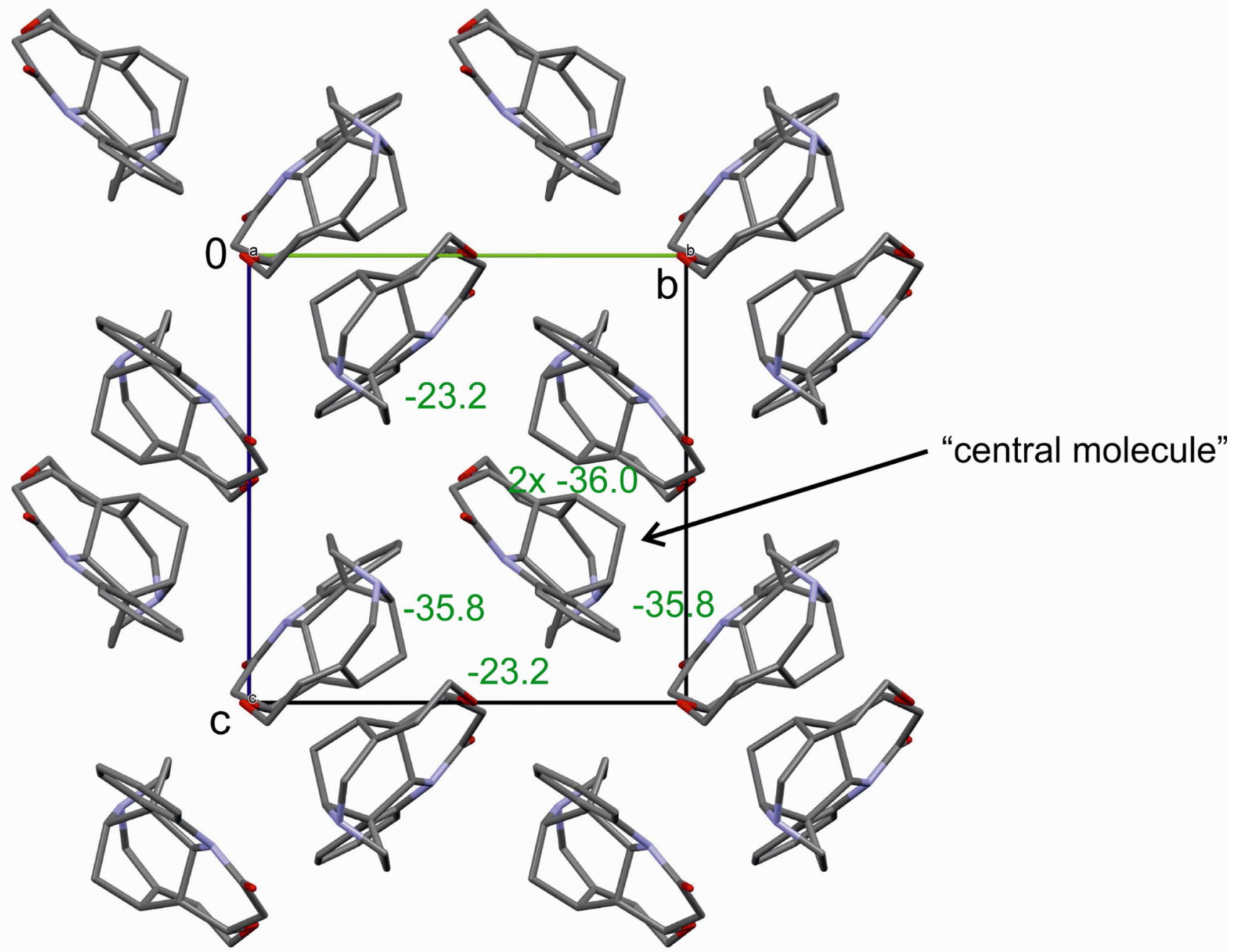

Figure 2.

Packing diagram of strychnine anhydrate52 viewed along the crystallographic a axis.

Hydrogen atoms are omitted for clarity. Numbers (green) are the pair-wise intermolecular PIXEL energies (Table 1). 


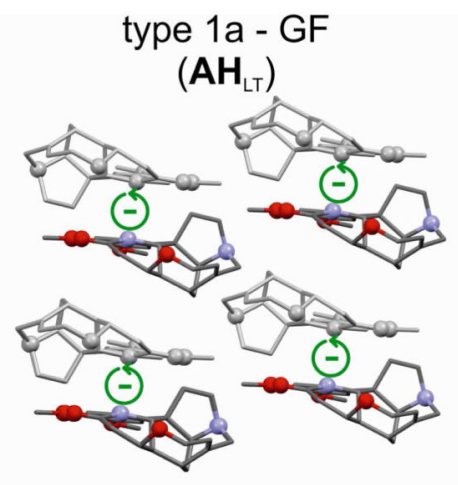

pe $1 \mathrm{a}-\mathrm{GF}$

$\mathrm{H}_{\mathrm{LT}}$ )

type $2 a-\alpha$

(HyB, solvates)
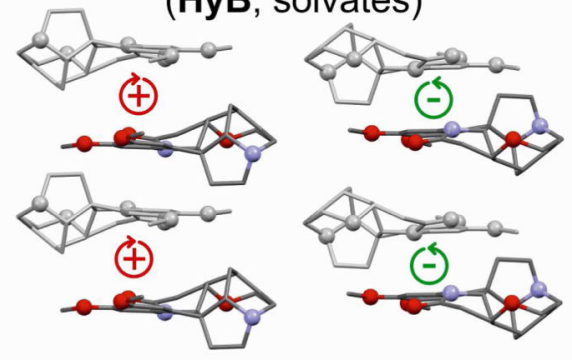

type $1 b$

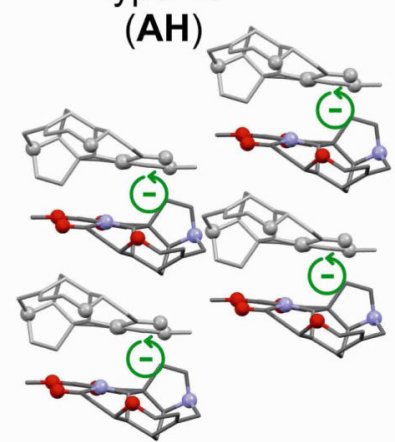

type 1c

(HyC)

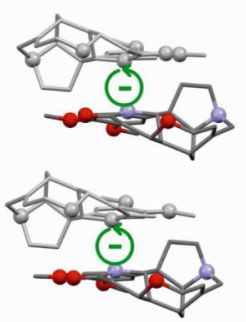

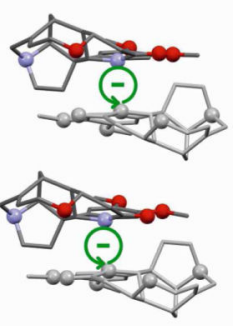

type $2 b-\beta$

(solvates)

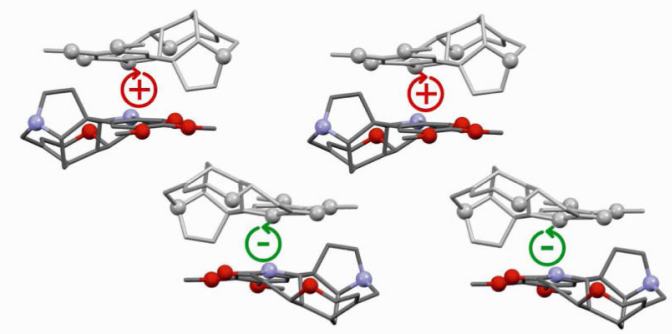

type 3

(5.25 hydrate)

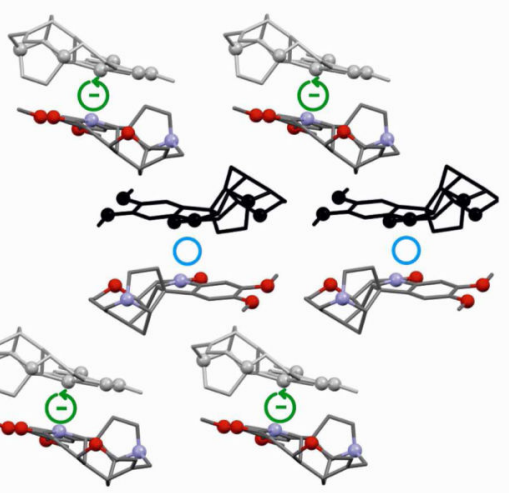

type 4

(HyA)

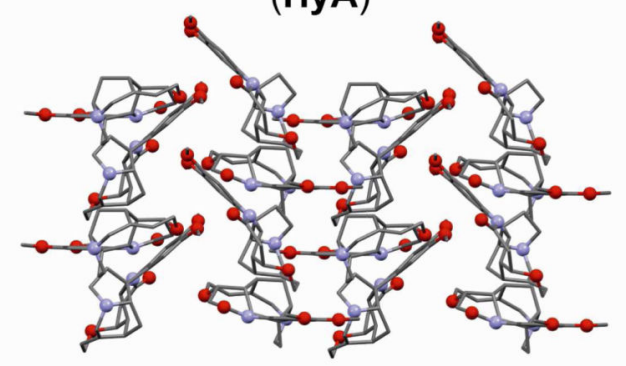

type 5 (acetone solvate)

Figure 3.

Packing diagrams of the eigth types of brucine (guest-free) structures. Note that type 1a corresponds to GF (Watabe et al.56), type 2a to the a-type and type $2 \mathrm{~b}$ to the $\beta$-type. "+" and "-" symbols denote the right and left handedness of the helical tapes and empty circles 2-fold axes (Figure 4). 

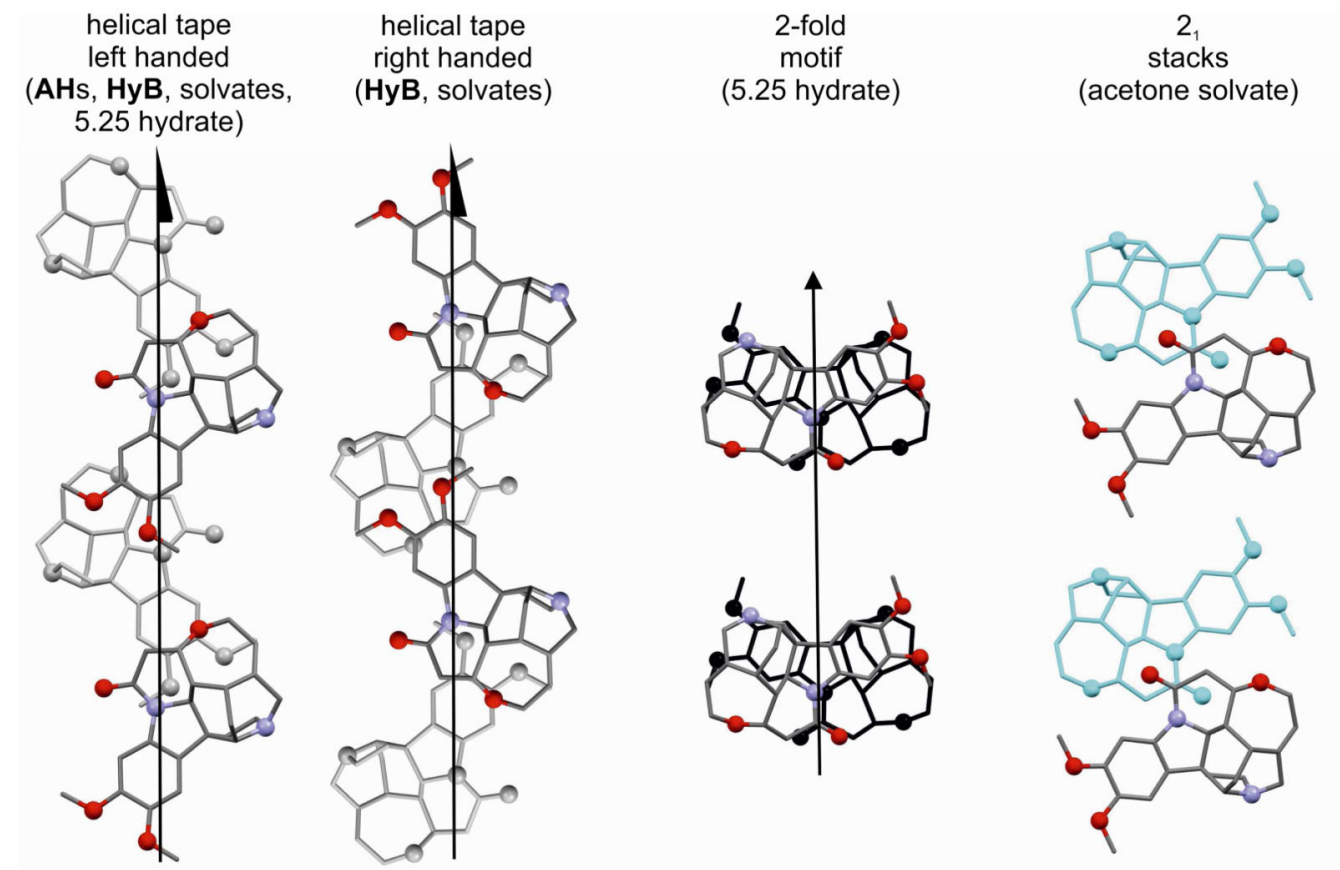

(acetone solvate)

$Z^{\prime}=2$

motif

(HyA)
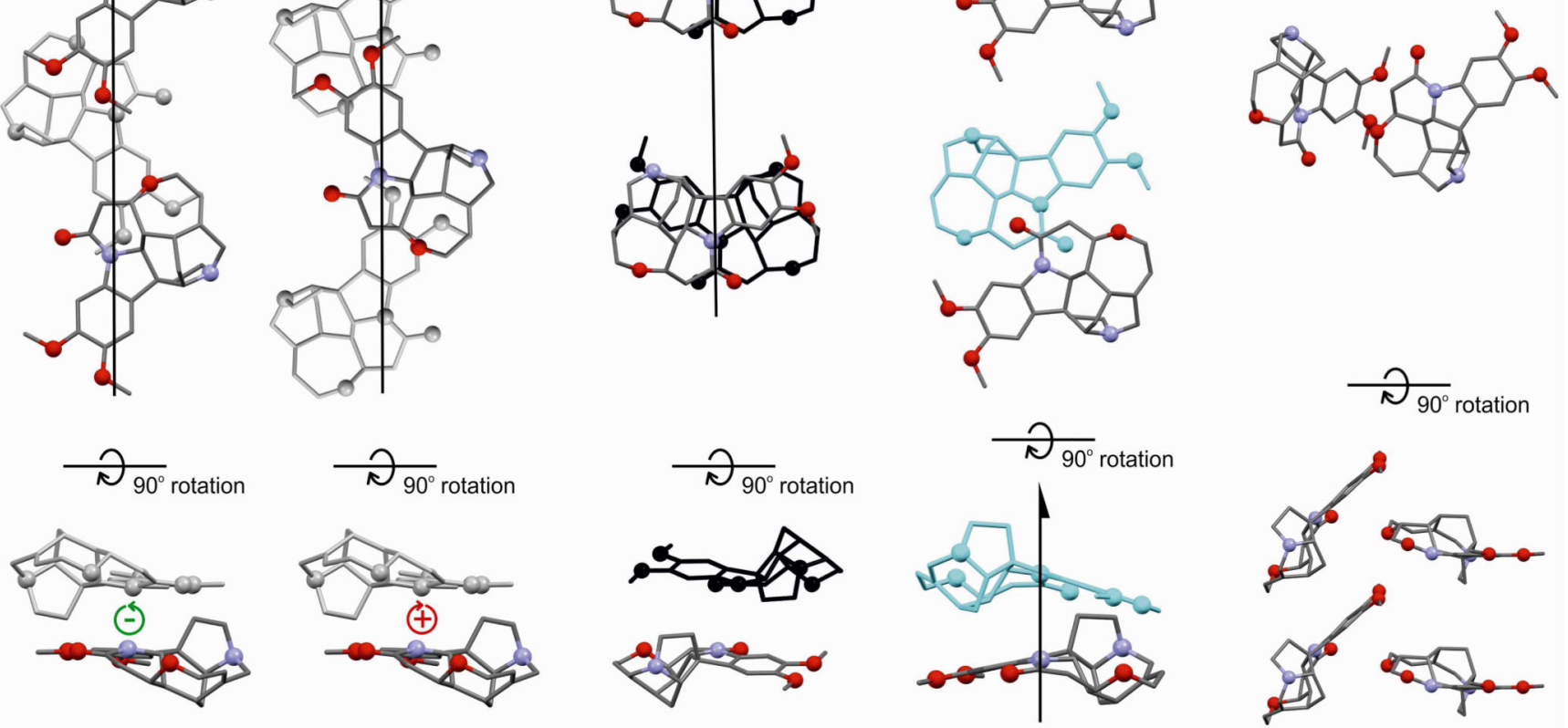

Figure 4.

Brucine (guest-free) packing motifs found in structure types $1-5$ (Figure 3).

Cryst Growth Des. Author manuscript; available in PMC 2017 November 02. 
(a) $\mathrm{AH}_{\mathrm{LT}}$

(b) $\mathrm{AH}$

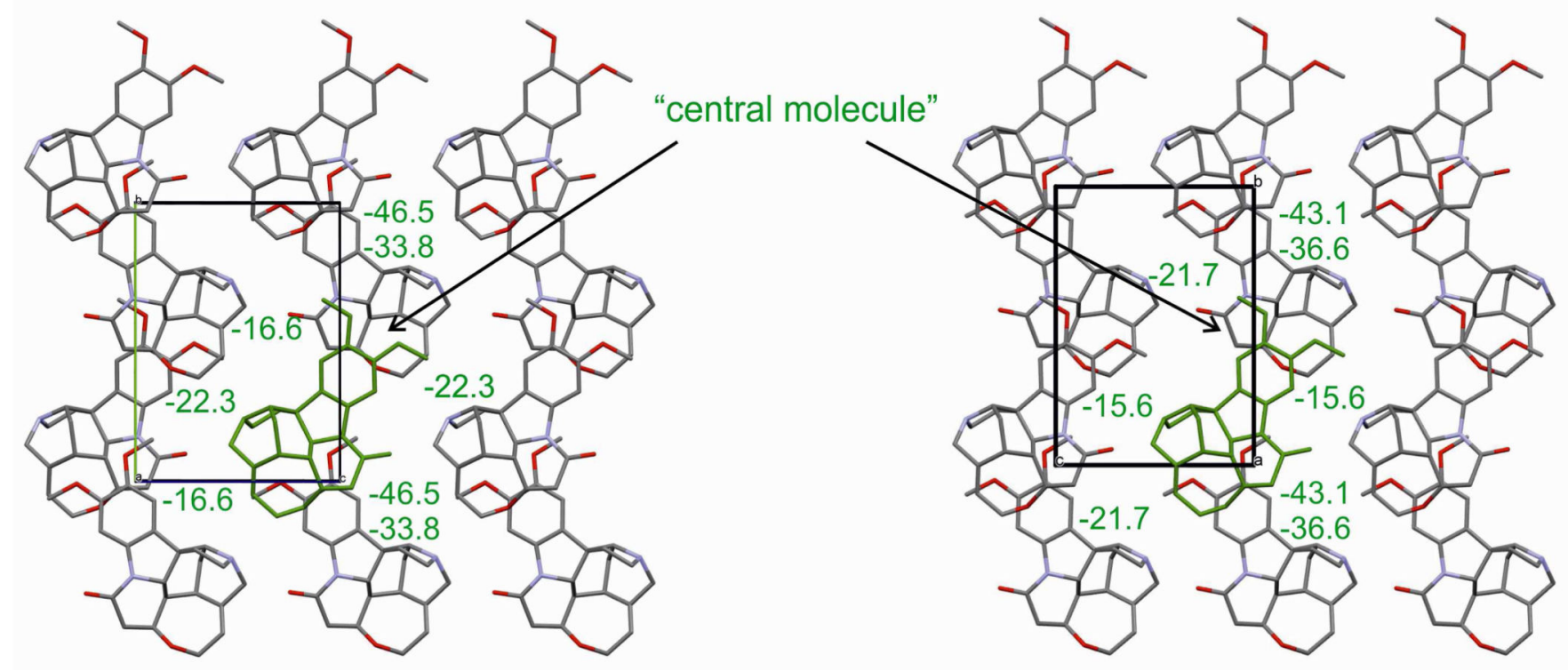

Figure 5.

Packing diagram of brucine (a) $\mathbf{A H}_{\mathbf{L T}} 54$ and (b) $\mathbf{A H}$ viewed along the crystallographic a axes. Hydrogen atoms are omitted for clarity. Numbers (green) are the pair-wise intermolecular PIXEL energies (Table 2). 

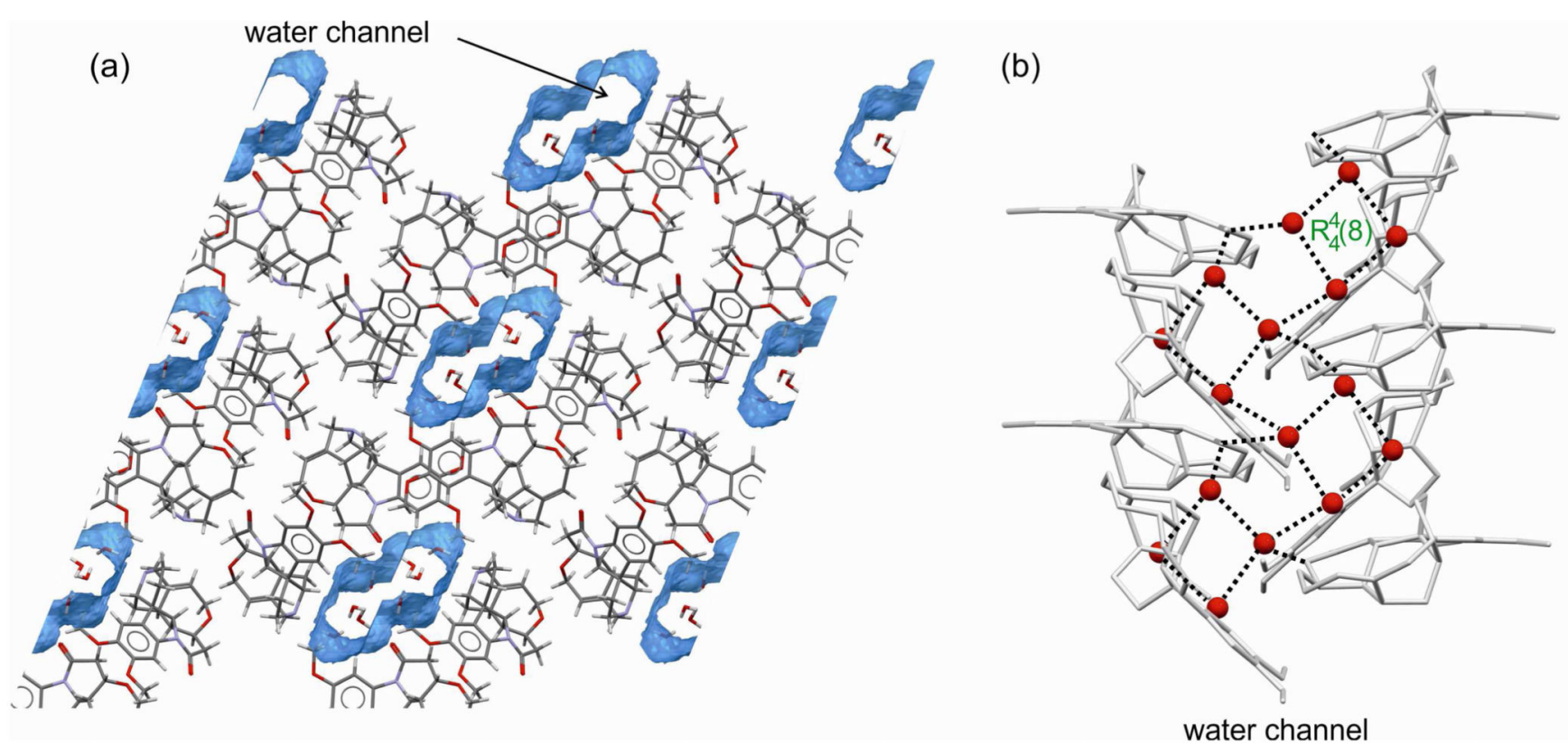

Figure 6.

(a) Free accessible volume analysis of HyA (CIKDOQ58), excluding the water molecules, showing the water channels along the crystallographic $b$ axis. Water space was calculated using the Hydrate Analyzer tool in Mercury and a probe radius and approx. grid spacing of 1.2 and $0.15 \AA$, respectively. (b) Hydrogen bonded chain of water molecules viewed along ac. 

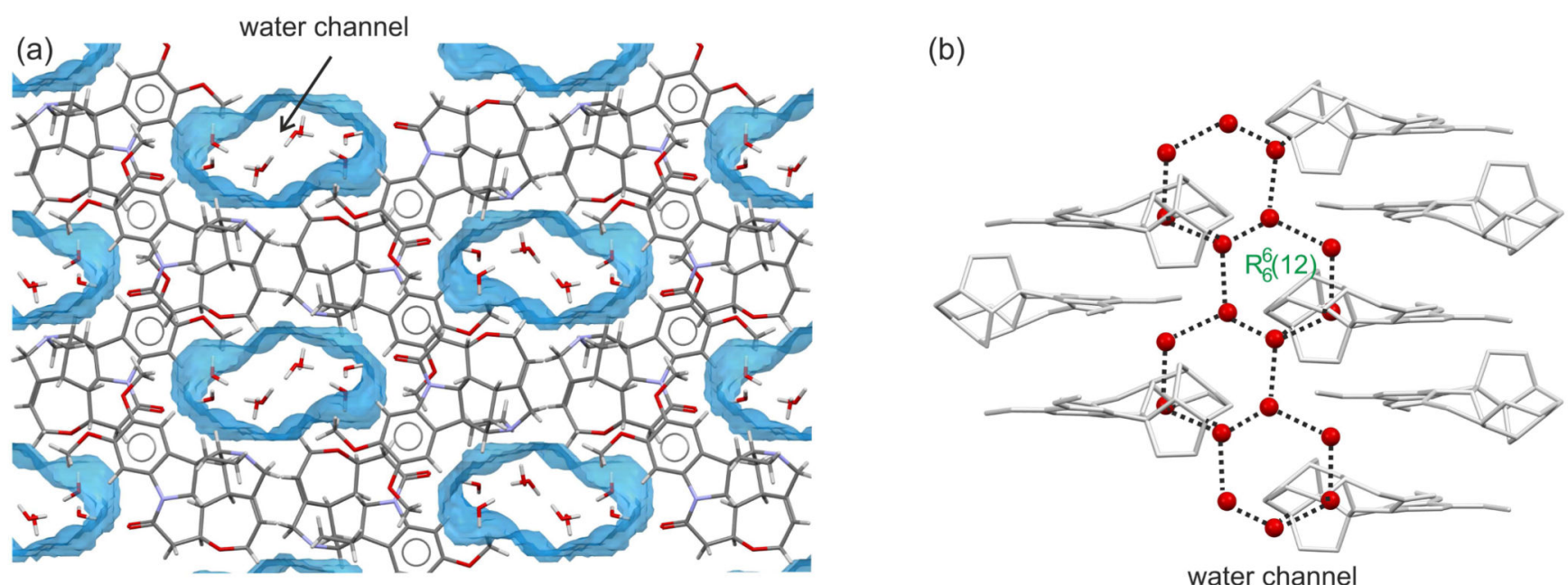

Figure 7.

(a) Free accessible volume analysis of HyB (ZZZPRW0159), excluding the water molecules, showing the water channels along the crystallographic $a$ axis. Water space was calculated using the Hydrate Analyzer tool in Mercury and a probe radius and approx. grid spacing of 1.2 and $0.15 \AA$, respectively. (b) Hydrogen bonded chain of water molecules viewed along $b$. 


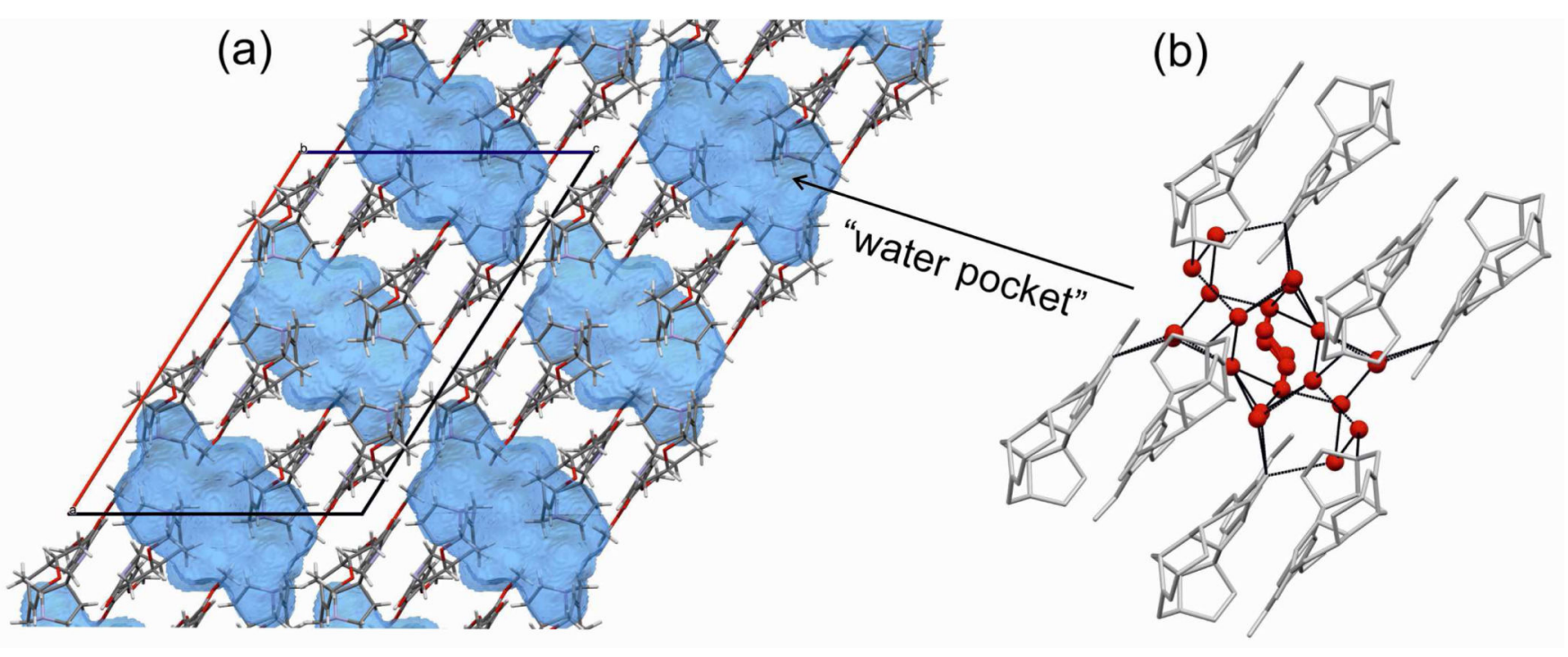

Figure 8.

(a) Free accessible volume analysis of HyC (YOYZIX55), excluding the water molecules, showing the water pockets. Water space was calculated using the Hydrate Analyzer tool in Mercury and a probe radius and approx. grid spacing of 1.2 and $0.15 \AA$, respectively. (b) HyC water cluster viewed along $b$. 

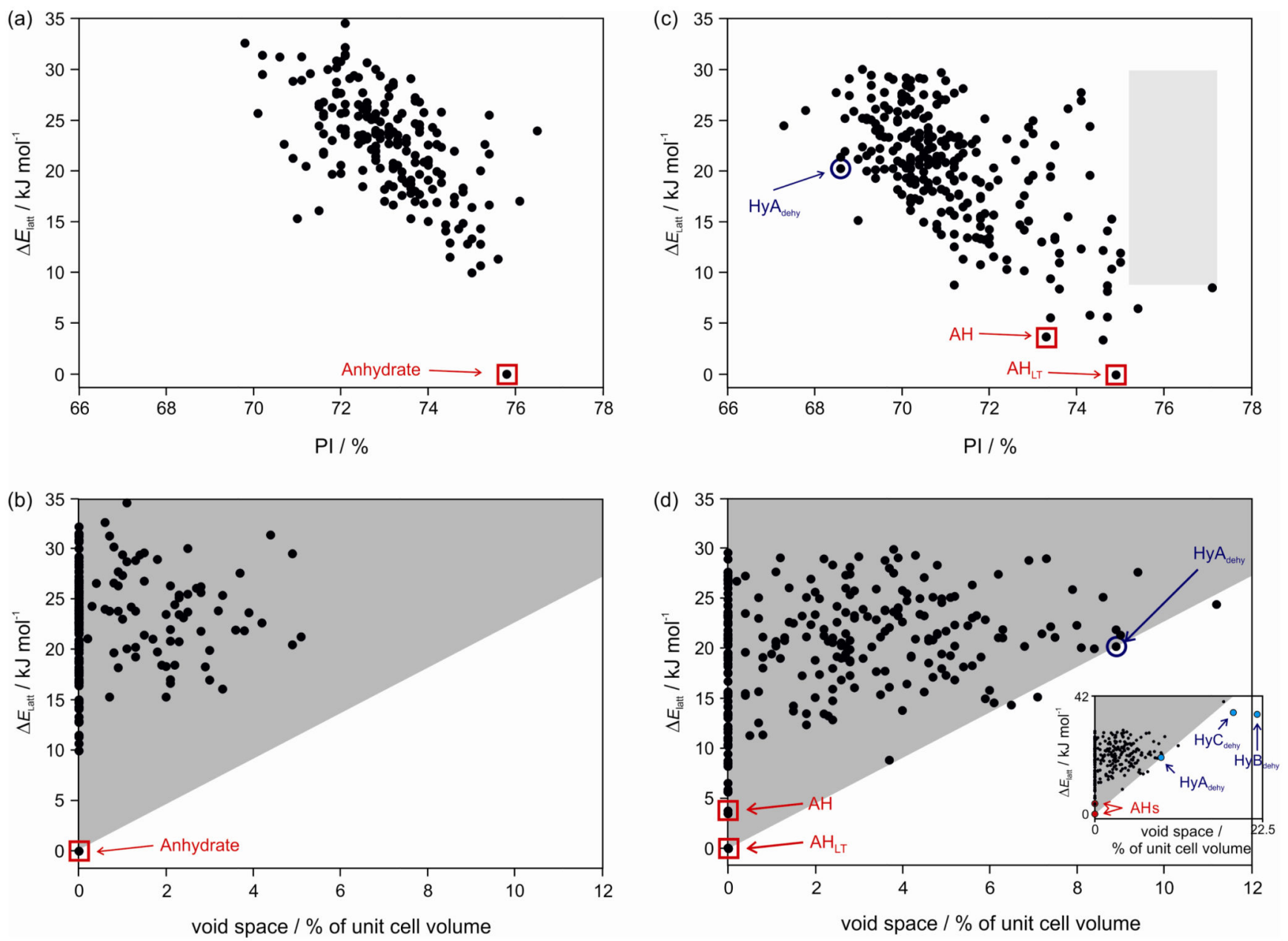

Figure 9.

Lowest energy crystal structures for $(a, b)$ strychnine and $(c, d)$ brucine generated in CSP searches (PBE-D2). In (a,c) the packing index (PI) and in $(b, d)$ the void space calculated using a $1.2 \AA$ probe radius and approx. grid spacing of $0.15 \AA$ are plotted against lattice energy differences $\left(\Delta E_{\text {latt }}\right)$, respectively. Light grey area in (c) marks the region of "excluded" structures (see section 2.3.). Grey areas on (b,d) correspond to the same void space and $\Delta E_{\text {latt }}$ range. The inset in (d) shows the extended void space $-\Delta E_{\text {latt }}$ range, including the computational $\mathbf{H y B} \mathbf{B}_{\text {dehy }}$ and $\mathbf{H y} \mathbf{C}_{\text {dehy }}$ dehydrate structures. The structures in .res format are available from the authors on request. 

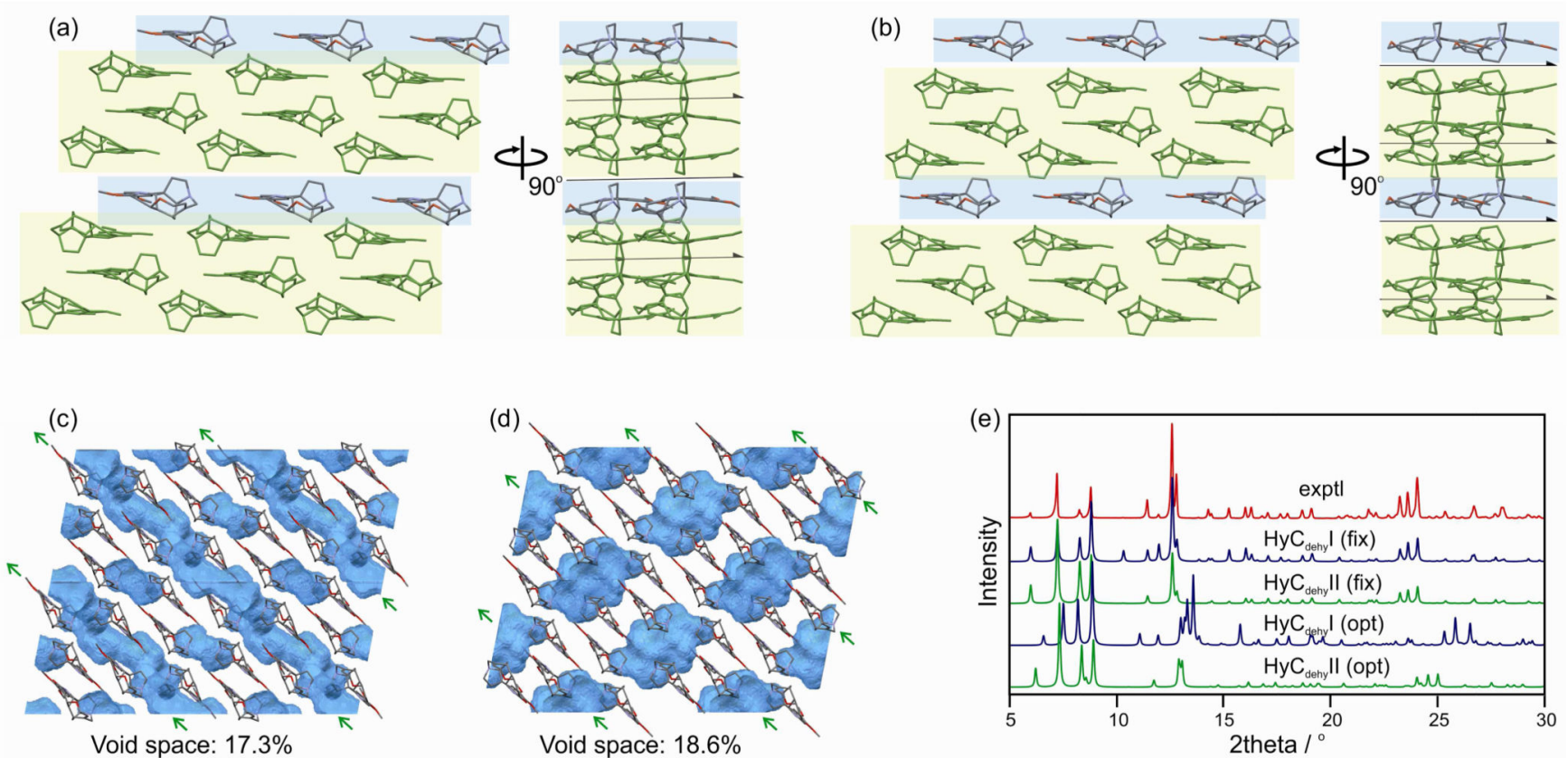

Figure 10.

Packing diagrams of (a) $\mathbf{H y} \mathbf{C}_{\mathbf{d e h y}} \mathbf{I}$ and (b) $\mathbf{H y} \mathbf{C}_{\text {dehy }}$ II viewed along the crystallographic $b$ axis (left figures). Brucine molecules colored in green (and yellow background) indicate the common packing motif in (a) and (b). Void space analysis of (c) $\mathbf{H y} \mathbf{C}_{\mathbf{d e h y}} \mathbf{I}$ and (d)

$\mathbf{H y C}_{\text {dehy }}$ II. Water space was calculated using the Hydrate Analyzer tool in Mercury and a probe radius and approx. grid spacing of 1.2 and $0.15 \AA$, respectively. Arrows indicate the structural difference, shifted brucine layers, between the two structures. (e) Comparison of experimental and computed, simulated from $\mathbf{H y} \mathbf{C}_{\mathbf{d e h y}} \mathbf{I}$ and $\mathbf{H y} \mathbf{C}_{\mathbf{d e h y}} \mathbf{I I}$ structures, powder $\mathrm{X}$-ray diffraction patterns. Structure minimizations were performed either by optimizing lattice parameters and atomic positions (opt) using CASTEP or keeping the lattice parameters fixed to the experimental values and optimizing the atomic positons only (fix). 


\section{Table 1}

PIXEL energy calculations on strychnine anhydrate (PBE-TS optimized structure, see section 3.3). Only the most relevant intermolecular interactions for pairs of molecules are listed.

\begin{tabular}{|c|c|c|c|c|c|c|}
\hline \multirow[t]{2}{*}{$1 \cdots \mathbf{m}^{a}$} & \multirow[t]{2}{*}{ Symmetry } & $E_{\mathrm{C}}^{b}$ & $E_{\mathbf{P}}{ }^{c}$ & $E_{\mathrm{D}}^{d}$ & $E_{\mathrm{R}}{ }^{e}$ & $U_{\text {inter }}$ \\
\hline & & \multicolumn{5}{|c|}{$\mathbf{k J} \mathbf{~ m o l}^{-1}$} \\
\hline $2 ; 3$ & $0.5+x, 0.5-y, 1-z,-0.5+x, 0.5-y, 1-z$ & -20.2 & -11.3 & -55.9 & 51.5 & -36.0 \\
\hline $4 ; 5$ & $1-x, 0.5+y, 1.5-z, 1-x,-0.5+y, 1.5-z$ & -25.0 & -14.5 & -58.5 & 62.2 & -35.8 \\
\hline $6 ; 7$ & $0.5-x,-y, 0.5+z ; 0.5-x,-y,-0.5+z$ & -11.0 & -5.3 & -27.6 & 20.6 & -23.2 \\
\hline
\end{tabular}

${ }^{a}$ PIXEL energies are for a pair of molecules $(\mathrm{m})$. The pairs of molecules are defined by symmetry relation

$b_{\text {electrostatic (Coulombic) energy }}$

polarization energy

$d_{\text {dispersion energy }}$

repulsion energy

$f$ total intermolecular energy: $U_{\mathrm{inter}}=E \mathrm{C}+E \mathrm{P}+E \mathrm{D}+E \mathrm{R}$. The non-additivity of $E \mathrm{P}$ is not included. 


\section{Table 2}

PIXEL energy calculations for brucine anhydrates (PBE-TS optimized structure, see section 3.3). Only the most relevant intermolecular interactions for pairs of molecules are listed.

\begin{tabular}{|c|c|c|c|c|c|c|c|}
\hline \multirow[t]{2}{*}{$1 \cdots \mathbf{m}^{a}$} & \multirow[t]{2}{*}{ Solid Form } & \multirow[t]{2}{*}{ Symmetry } & $E_{\mathrm{C}}^{b}$ & $E_{\mathrm{P}}{ }^{c}$ & $E_{\mathrm{D}}^{d}$ & $E_{\mathrm{R}}^{e}$ & $U_{\text {inter }} f$ \\
\hline & & & \multicolumn{5}{|c|}{$\mathrm{kJ} \mathrm{mol}{ }^{-1}$} \\
\hline \multirow[t]{2}{*}{$2 ; 3$} & $\mathbf{A H}_{\mathrm{LT}}$ & $1-x, 0.5+y, 1-z, 1-x,-0.5+y, 1-z$ & -26.4 & -13.6 & -67.2 & 60.7 & -46.5 \\
\hline & $\mathbf{A H}$ & $1-x, 0.5+y,-z, 1-x,-0.5+y,-z$ & -24.0 & -11.6 & -59.9 & 52.5 & -43.1 \\
\hline \multirow[t]{2}{*}{$4 ; 5$} & $\mathbf{A H}_{\mathrm{LT}}$ & $-x, 0.5+y, 1-z,-x,-0.5+y, 1-z$ & -27.6 & -12.4 & -54.8 & 61.0 & -33.8 \\
\hline & $\mathbf{A H}$ & $2-x, 0.5+y,-z, 2-x,-0.5+y,-z$ & -25.5 & -12.5 & -57.6 & 58.9 & -36.6 \\
\hline \multirow[t]{2}{*}{$6 ; 7$} & $\mathbf{A H}_{\mathbf{L T}}$ & $x, y, 1+z, x, y,-1+z$ & -14.1 & -9.6 & -34.9 & 35.8 & -22.8 \\
\hline & $\mathbf{A H}$ & $1+x, y, 1+z,-1+x, y,-1+z$ & -4.8 & -2.7 & -15.7 & 7.6 & -15.6 \\
\hline \multirow[t]{2}{*}{$8 ; 9$} & $\mathbf{A H}_{\mathrm{LT}}$ & $-x, 0.5+y,-z ;-x,-0.5+y,-z$ & -6.1 & -4.7 & -28.8 & 23.0 & -16.6 \\
\hline & $\mathbf{A H}$ & $2-x, 0.5+y, 1-z, 2-x,-0.5+y, 1-z$ & -14.3 & -8.2 & -26.6 & 37.1 & -21.7 \\
\hline
\end{tabular}

${ }^{a}$ PIXEL energies are for a pair of molecules (m). The pairs of molecules are defined by symmetry relation;

$b$

$b$ electrostatic (Coulombic) energy;

polarization energy;

$d_{\text {dispersion energy; }}$

repulsion energy;

total intermolecular energy: $U_{\text {inter }}=E_{\mathrm{C}}+E_{\mathrm{P}}+E_{\mathrm{D}}+E_{\mathrm{R}}$. The non-additivity of $E_{\mathrm{P}}$ is not included. 


\section{Table 3}

Calculated $0 \mathrm{~K}$ potential energy differences $\left(\Delta_{\text {trs }} U\right)$ between brucine solid forms $\left(\mathbf{H y A}\right.$ - hydrate A, Hy $\mathbf{A}_{\text {dehy }}$ - isomorphous HyA dehydrate, $\mathbf{A H}$ - anhydrate).

\begin{tabular}{|c|c|c|}
\hline Method $^{a}$ & $\Delta_{\text {trs }} U_{\text {HyA-HyA(dehy) }}$ & $\Delta_{\text {trs }} U_{\text {HyA-AH }}$ \\
\hline & \multicolumn{2}{|c|}{$\mathbf{k J} \mathbf{~ m o l}^{-1}$} \\
\hline$\Psi_{\mathrm{mol}}: \operatorname{PBE} 0 / 6-31 \mathrm{G}(\mathrm{d}, \mathrm{p})^{b}$ & 6.10 & -6.43 \\
\hline$\Psi_{\text {mol }}:$ PBE0/6-31G(d,p), PCM $(\varepsilon=3)^{c}$ & 5.15 & -8.44 \\
\hline$\Psi_{\text {cry }}:$ PBE-TS $^{d}$ & 16.33 & -0.16 \\
\hline$\Psi_{\text {cry }}:$ PBE-D $2^{d}$ & 7.86 & -8.03 \\
\hline RH-Perfusione ${ }^{e}, 37$ & $5.3 \pm 0.9$ & - \\
\hline $\operatorname{DSC}(\text { closed })^{e}, 37$ & - & $3.0 \pm 0.9$ \\
\hline $\operatorname{DSC}(\text { open) })^{e}, 37$ & - & $2.4 \pm 1.0$ \\
\hline
\end{tabular}

${ }^{a}$ Ab initio electronic calculations on either the single molecule ( $\left.\Psi_{\mathrm{mol}}\right)$ or crystal ( $\left.\Psi_{\text {cry }}\right)$.

$b_{\operatorname{Re} a x}$

Relaxed structures using the CrystalOptimizer methodology;

${ }^{c}$ relaxed structures with average polarization from the PCM model. The effect of simulating the average polarization of the molecule within the crystal structure was tested by calculating the distributed multipoles and relative conformational energies using the polarizable continuum model (PCM)90-92 implemented in GAUSSIAN09 with $\varepsilon=3$, a value typical of organic crystals93;

${ }^{d}$ CASTEP density functional theory relaxations with dispersion correction ( $k$-points: $0.07 \AA^{-1}$, cut-off: $780 \mathrm{eV}$, lattice parameters and atomic positions optimized).

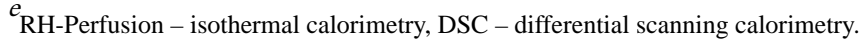


Table 4

Lattice energy comparison (expressed as $\Delta E_{\text {latt }}$ with respect to $\mathbf{A H}$ ) of $\mathbf{H y A}-\mathbf{H y C}$ computational dehydrates.

\begin{tabular}{cccc}
\hline Dehydrate structure $^{\boldsymbol{a}}$ & $\mathbf{H y A}_{\text {dehy }}$ & $\mathbf{H y B}_{\text {dehy }}$ & $\mathbf{H y C}_{\mathbf{d e h y}}$ \\
\hline water:brucine ratio & $2: 1$ & $4: 1$ & $3.85: 1$ \\
\hline $\begin{array}{c}\Delta E_{\mathrm{latt}} / \mathrm{kJ} \mathrm{mol}^{-1} \\
(\mathrm{PBE}-\mathrm{D} 2)^{b}\end{array}$ & 20.15 & 35.53 & 36.18 \\
\hline void space / \% of unit cell volume $^{c}$ & 8.9 & 21.8 & 18.6 \\
\hline void space / form & channel & channel & pockets \\
\hline
\end{tabular}

a Solvent molecules were removed from the structures and the solvent stripped structures optimized using the same methodology as used for generating Figure 9a.

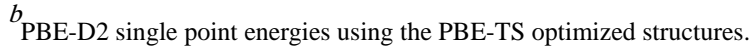

$c^{c}$ Void space was calculated using the Hydrate Analyzer tool in Mercury and a probe radius and approx. grid spacing of 1.2 and $0.15 \AA$, respectively. 